\title{
Tidal and Near-Inertial Internal Waves over the Reykjanes Ridge
}

\author{
Clément Vic, ${ }^{\mathrm{a}}$ Bruno Ferron, ${ }^{\mathrm{a}}$ Virginie Thierry, ${ }^{\mathrm{a}}$ Herlé Mercier, ${ }^{\mathrm{a}}$ And Pascale Lherminier $^{\mathrm{a}}$ \\ ${ }^{\text {a } U n i v . ~ B r e s t, ~ C N R S, ~ I R D, ~ I f r e m e r, ~ L a b o r a t o i r e ~ d ' O c e ́ a n o g r a p h i e ~ P h y s i q u e ~ e t ~ S p a t i a l e, ~ I U E M, ~ P l o u z a n e ́, ~ F r a n c e ~}$
}

(Manuscript received 7 May 2020, in final form 4 November 2020)

\begin{abstract}
Internal waves in the semidiurnal and near-inertial bands are investigated using an array of seven moorings located over the Reykjanes Ridge in a cross-ridge direction $\left(57.6^{\circ}-59.1^{\circ} \mathrm{N}, 28.5^{\circ}-33.3^{\circ} \mathrm{W}\right)$. Continuous measurements of horizontal velocity and temperature for more than 2 years allow us to estimate the kinetic energy density and the energy fluxes of the waves. We found that there is a remarkable phase locking and linear relationship between the semidiurnal energy density and the tidal energy conversion at the spring-neap cycle. The energy-to-conversion ratio gives replenishment time scales of 4-5 days on the ridge top versus 7-9 days on the flanks. Altogether, these results demonstrate that the bulk of the tidal energy on the ridge comes from near-local sources, with a redistribution of energy from the top to the flanks, which is endorsed by the energy fluxes oriented in the cross-ridge direction. Implications for tidally driven energy dissipation are discussed. The time-averaged near-inertial kinetic energy is smaller than the semidiurnal kinetic energy by a factor of 2-3 but is much more variable in time. It features a strong seasonal cycle with a winter intensification and subseasonal peaks associated with local wind bursts. The ratio of energy to wind work gives replenishment time scales of 13-15 days, which is consistent with the short time scales of observed variability of near-inertial energy. In the upper ocean $(1 \mathrm{~km})$, the highest levels of near-inertial energy are preferentially found in anticyclonic structures, with a twofold increase relative to cyclonic structures, illustrating the funneling effect of anticyclones.
\end{abstract}

KEYWORDS: Diapycnal mixing; Inertia-gravity waves; Wave properties; Tides; In situ oceanic observations

\section{Introduction}

The strength and pathway of the deep branch of the meridional overturning circulation (MOC) are intricately linked to irreversible mixing through density surfaces, called diapycnal mixing. The winds and tides are the main energy sources of the MOC: they provide the bulk of the energy that fuels the amount of diapycnal mixing needed to sustain the MOC (Munk and Wunsch 1998; Wunsch and Ferrari 2004). From those two sources, the energy pathway leading to diapycnal mixing involves the generation of internal waves in the boundary layers (the wind generates near-inertial waves and the interaction of astronomical tides with the seafloor topography generates internal tides), the propagation of these waves into the ocean interior, and their ultimate breaking into turbulence [see Whalen et al. (2020) for an extensive review of the subject].

Because of their first-order role in driving mixing, internal tides have been intensively investigated over the last decades, leading to significant advances in our understanding of their life cycle, from generation to dissipation. Our current knowledge of tidally driven mixing could be summarized as follows. First, we know rather accurately the geography of the energy conversion of astronomical tides into internal tides (e.g., Nycander 2005; Pollmann et al. 2019). Second, we can broadly quantify internal tides propagation in the ocean, at least for the low-mode, that is, large-scale, waves (e.g., Alford 2003b; Rainville and Pinkel 2006; Zhao et al. 2016; Ansong et al. 2017; Waterhouse et al. 2018). Third, we are constantly refining our understanding of how waves interact with their environment

Corresponding author: Clément Vic, cvic@univ-brest.fr and loose energy, for example through wave-wave interactions (Gregg 1989; Polzin 2004; Olbers et al. 2020) or scattering over seafloor topography (Bühler and Holmes-Cerfon 2011; Lahaye and Llewellyn Smith 2020). Using scaling laws for the processes leading to wave dissipation, the community is currently mapping internal tide dissipation (de Lavergne et al. 2019, 2020; Vic et al. 2019). Uncertainties remain, among others, on the interactions of internal tides with balanced flows, and the variability of the energy propagation paths and intensity (e.g., Chiswell 2006; Köhler et al. 2019), due a lack of sustained observations with a broad spatial coverage.

The role of the wind in driving mixing below the mixed layer is less documented. Although we know the geography and seasonality of energy transfer into near-inertial waves (e.g., Watanabe and Hibiya 2002; Alford 2003a; Flexas et al. 2019), how near-inertial energy propagates and is ultimately transferred to turbulence remain poorly observed and unclear (Garrett 2001; Alford et al. 2016). Observations highlighted a clear seasonal cycle of near-inertial kinetic energy down to $4000 \mathrm{~m}$, with a winter intensification related to the generation of internal waves by synoptic low pressure atmospheric systems (D'Asaro 1985; Alford and Whitmont 2007; Silverthorne and Toole 2009). Hence, wind-modulated turbulent mixing potentially impacts the deep branch of the MOC, as found in idealized numerical experiments (Jouanno et al. 2016).

This paper addresses the spatial and temporal variability of internal tides and near-inertial waves over the Reykjanes Ridge, the northern extension of the Mid-Atlantic Ridge, using 2 years of observations from an array of seven moorings (Fig. 1). As do many other ridge systems, the Reykjanes Ridge generates internal tides, whose breaking is thought to be responsible for 

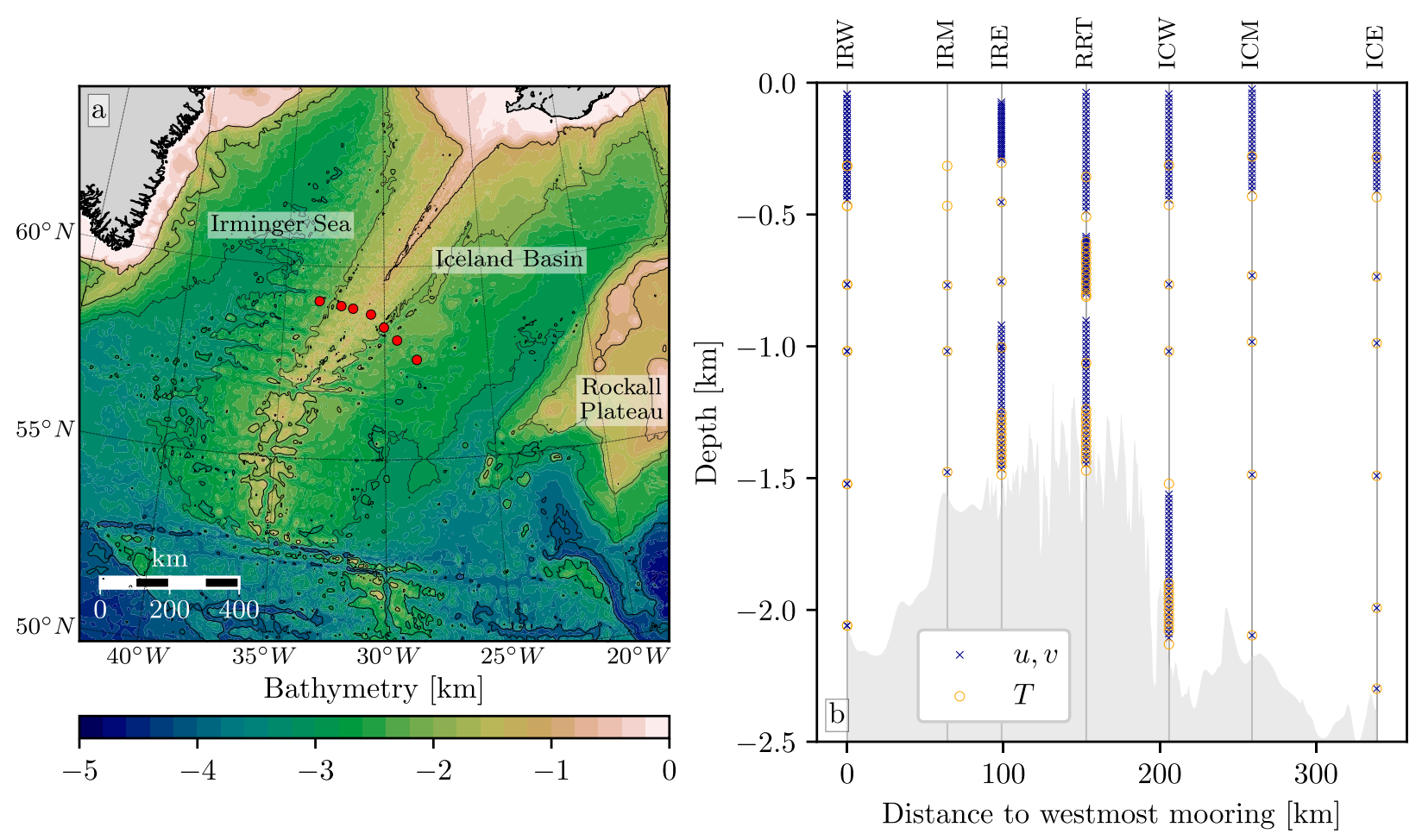

FIG. 1. (a) Bathymetric chart of the area of interest. The Reykjanes Ridge separates the Irminger Sea from the Iceland Basin. The landmass in the northwest corner is Greenland, and that in the northeast is Iceland. Black lines are bathymetry contours $-1,-2,-3$, and $-4 \mathrm{~km}$, and the red dots show the locations of the moorings. Bathymetry is from SRTM30 (Becker et al. 2009). (b) Section through the mooring array showing bathymetry (gray shadings) and mooring measurements. Each blue cross represents a horizontal velocity measurement, either from an ADCP or a current meter. Each orange circle represents a temperature measurement. Mooring names are written at the top: IRW, IRM, and IRE stand for Irminger Sea West, Middle, and East; RRT stands for Reykjanes Ridge Top; and ICW, ICM, and ICE stand for Iceland Basin West, Middle, and East.

the enhanced energy dissipation (Ferron et al. 2016). Its location at high latitudes in the Northern Hemisphere also potentially makes it home to a seasonal wind-driven near-inertial wave field. Located in the middle of the North Atlantic Ocean subpolar gyre, the Reykjanes Ridge poses several constrains on the ocean circulation mean state and variability. Notably, it affects the barotropic circulation (Petit et al. 2018; Le Corre et al. 2020), steers the dense water overflows from the Nordic seas (Bower and Furey 2017), and is situated at the gateway of dense waters formed by winter deep convection (Piron et al. 2017). Recently, the Overturning in the Subpolar North Atlantic Program (OSNAP) identified the southward transport of dense waters in the Irminger and Iceland basins as being the main driver of the MOC in the subpolar gyre (Lozier et al. 2019), further highlighting the key location of the Reykjanes Ridge at a crossroad of the Atlantic MOC. Nonetheless, the high-frequency dynamics occurring over the ridge has been overlooked, despite being a conduit to energy dissipation, mixing, and subsequent water mass transformation.

The work presented here is part of the Reykjanes Ridge Experiment project (RREX; Petit et al. 2018, 2019). RREX seeks to clarify the role of the ridge in the circulation of the subpolar gyre. As part of this project, and also integrated to OSNAP, an array of seven moorings was deployed for 2 years in a cross-ridge direction (Fig. 1). Moorings were designed to recover some of internal waves' properties, that is, kinetic energy density and energy fluxes. We combined these in situ measurements with independent estimates of power input by the winds and tides to rationalize the observations.

The paper is organized as follows. In sections 2 and 3, we introduce the data and methods used in this study, respectively. Section 4 presents the results, including internal tides and nearinertial waves' properties and variability inferred from the mooring array. We sum up the results and discuss their implications in section 5 .

\section{Data}

\section{a. Mooring data}

The mooring array was deployed in a cross-ridge direction in the area $57.6^{\circ}-59.1^{\circ} \mathrm{N}, 28.5^{\circ}-33.3^{\circ} \mathrm{W}$ on $16-28$ June 2015 and was recovered on 23-28 July 2017 (exact positions are given in Table 1 and Fig. 1a). Three moorings were deployed in the Irminger Sea side, named IRW (west), IRM (middle), and IRE (east); one mooring was deployed on top of the ridge, named RRT (Reykjanes Ridge top); and three moorings were deployed on the Iceland Basin side, named ICW (west), ICM 


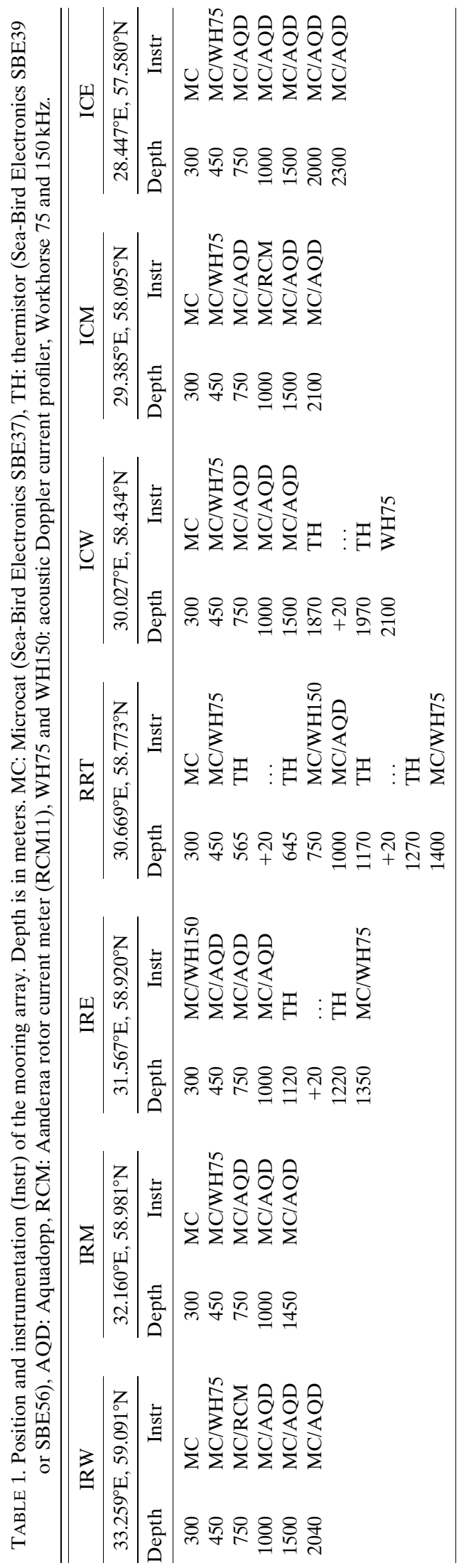

(middle), and ICE (east). Details on the operations can be found in the cruise reports (Branellec and Thierry 2016, 2018). Moorings recorded horizontal velocity with Teledyne WorkHorse 75- and 150-kHz acoustic Doppler current profilers (ADCPs), Aanderaa Doppler current meters (RCM11), and Nortek Aquadopp current meters. They recorded temperature and salinity with Sea-Bird Electronics Microcats (SBE37) and temperature only with chains of thermistors (SBE39 and SBE56). Instruments' target depths are indicated in Table 1, and mean depths over the deployment are shown in Fig. 1b. All instruments recorded data almost continuously for 2 years, apart from IRM's ADCP, which did not return any data.

The $75-\mathrm{kHz}$ ADCPs recorded velocity every $180 \mathrm{~s}$ with $16-\mathrm{m}$ vertical bins and the $150 \mathrm{-kHz}$ ADCPs recorded velocity every $30 \mathrm{~s}$ with $8-\mathrm{m}$ vertical bins, using a single ping per ensemble to save up energy for the long-term deployment. Data quality was overall very good at all depths, except for the velocity measurements close to the surface performed by the upward-looking ADCPs. Spiky and noisy patterns were often found in winter, concurrent with storm events, sometimes down to $200 \mathrm{~m}$. We identified them as the deep signature of storm-induced surface swell. Broadly, we estimated the depth reached by swell-induced orbital velocity from the swell period and the wave height predicted by WAVEWATCH III (WAVEWATCH III Development Group 2016). These depths compared well to the depths down to which data quality was dubious. We flagged these data as bad and discarded them from subsequent analyses. Details of the procedure can be found in Balem (2019).

Aquadopp and RCM current meters recorded velocity every $600 \mathrm{~s}$ (average over a signal sampled at $23 \mathrm{~Hz}$ ) and 3600 s (150 pings per ensemble), respectively. Microcats and thermistors recorded temperature every 120 and 10 s, respectively. Salinity data showed drifts and frequent spikes, so we discarded them from the present analysis. Velocity and temperature data were averaged in time in 1-h bins, which permits us to reconstruct semidiurnal and near-inertial signals (the near-inertial period is $\sim 14.1 \mathrm{~h}$ at $58^{\circ} \mathrm{N}$ ) while smoothing out higher-frequency signals.

\section{b. Barotropic tidal currents}

We compute the barotropic tidal currents in the semidiurnal band at the time and location of mooring data using the Oregon State University Tidal Prediction Software (https://www.tpxo.net/otps) with TPXO9-atlas (Egbert and Erofeeva 2002). Time series of currents at 1 -h resolution allow us to identify a spring-neap cycle and deduce the ellipses' characteristics during spring tides and neap tides.

\section{c. Winds from a reanalysis product}

We use 10-m winds from ERA5, a global atmospheric reanalysis product computed by the European Centre for Medium-Range Weather Forecasts (Copernicus 2017). ERA5 replaced ERA-Interim and benefits from recent developments in model physics and data assimilation, in addition to an enhanced horizontal resolution of $0.25^{\circ}$ and an hourly frequency of outputs 
(Hersbach et al. 2019). The latter permits us to accurately represent the synoptic weather systems of the North Atlantic and in particular their near-inertial variability. We linearly interpolated the winds at each mooring location.

\section{d. Altimetry-derived horizontal velocity}

We use the geostrophic horizontal velocity $\left(u_{g}, v_{g}\right)$ derived from absolute dynamic topography on a $1 / 4^{\circ}$ global grid. Data were downloaded from the Copernicus Marine Environment Monitoring Service (delayed-time, "allsat" product); see the product user manual (http://resources.marine.copernicus.eu/ documents/PUM/CMEMS-SL-PUM-008-032-062.pdf).

\section{Methods}

\section{a. Kinetic energy density and horizontal energy fluxes from mooring data}

Internal wave kinetic energy density and horizontal energy fluxes are computed from mooring data following the method described in Nash et al. (2005), with some changes as in Vic et al. (2018). Internal wave velocity $\mathbf{u}^{\prime}$ is defined as

$$
\mathbf{u}^{\prime}(z, t)=\mathbf{u}(z, t)-\overline{\mathbf{u}}(z, t)-\overline{\mathbf{u}_{0}}(t),
$$

where $\mathbf{u}(z, t)$ is the instantaneous velocity and $\overline{\mathbf{u}}(z, t)$ is the velocity of the background, low-frequency flow. Hereinafter, the overbars denote variables that are not associated with internal wave signal; $\overline{\mathbf{u}_{0}}(t)$ is then defined by the baroclinicity condition $1 / H \int_{-H}^{0} \mathbf{u}^{\prime}(z, t) d z=0$, where $H$ is the local water depth. In practice, $\overline{\mathbf{u}}(z, t)$ is defined as the low-pass instantaneous velocity with a cutoff frequency of $0.5 f$, where $f$ is the local inertial period. This filters out most mesoscale to submesoscale motions before enforcing the baroclinicity condition (similar method in Zhao et al. 2010). Note that, as detailed below, the wave velocity is then bandpass filtered at the semidiurnal and near-inertial frequencies, so the resulting velocities are weakly sensitive to the cutoff frequency of the prior low-pass filtering.

The wave pressure $p^{\prime}(z, t)$ is defined as

$$
p^{\prime}(z, t)=p_{\text {surf }}(t)+\int_{z}^{0} \rho^{\prime}(\hat{z}, t) g d \hat{z},
$$

where $p_{\text {surf }}$ is the surface pressure, $g$ is the acceleration of gravity, and $\rho^{\prime}$ is the density perturbation associated with the wave. Variable $p_{\text {surf }}$ is not measured but is determined by the baroclinicity condition, $1 / H \int_{-H}^{0} p^{\prime}(z, t) d z=0$. Since we discard salinity measurements from the analyses, we cannot derive density directly. As an alternative, $\rho^{\prime}(z, t)$ is inferred from the vertical displacement of isotherms $\xi(z, t)$ relative to their mean position:

$$
\rho^{\prime}(z, t)=[\bar{\rho}(z, t) / g] \overline{N^{2}}(z, t) \xi(z, t),
$$

where $\bar{\rho}(z, t)$ and $\overline{N^{2}}(z, t)$ are the potential density and the buoyancy frequency computed with the TEOS-10 toolbox (McDougall and Barker 2011), from a temperature and salinity monthly climatology [World Ocean Atlas 2018 (WOA18);
Locarnini et al. 2018; Zweng et al. 2018], linearly interpolated to the space and time of mooring data. The vertical displacement of isotherms, $\xi(z, t)$, is given by

$$
\xi(z, t)=-T^{\prime}(z, t)\left[\partial_{z} \bar{T}(z)\right]^{-1},
$$

where $T^{\prime}(z, t)$ is the temperature anomaly relative to the lowpass temperature (cutoff frequency of $0.5 f$, the same as for wave velocity processing) and $\partial_{z} \bar{T}(z)$ is the vertical gradient of temperature computed from the WOA18 monthly data.

The variables $\mathbf{u}^{\prime}$ and $p^{\prime}$ are then bandpass filtered at the semidiurnal (labeled with a subscript "SD") and near-inertial (labeled with a subscript "NI") frequencies. The semidiurnal frequency $\omega_{\mathrm{SD}}$ is defined as the average of the dominant semidiurnal tidal frequencies, $\mathrm{M}_{2}$ and $\mathrm{S}_{2}$. We use a fourthorder Butterworth filter in the bandwidth $\left\{c^{-1} \omega, c \omega\right\}$ where $\omega \in$ $\left\{\omega_{\mathrm{SD}}, f\right\}$, and $c=1.07$ is the bandwidth parameter (e.g., Alford 2003b; Zhao et al. 2010; Vic et al. 2018). The bandwidth parameter is the largest value allowed by the inequality $c f<$ $c^{-1} \omega_{\mathrm{SD}}$; that is, we ensure that there is no overlap between the near-inertial and semidiurnal bandwidths. Note that because of the closeness of the inertial and semidiurnal frequencies at high latitudes the bandwidth of the filter is narrow relative to classic filters used in midlatitude studies (a value of $c=1.25$ is traditionally used; e.g., Alford 2003b). Sensitivity to the filtering parameter is discussed in section $4 \mathrm{a}$.

The kinetic energy densities in the two wave bands are defined as

$$
E_{\mathrm{SD}}=\frac{1}{2} \rho_{0}\left|\mathbf{u}_{\mathrm{SD}}^{\prime}\right|^{2} \quad \text { and } \quad E_{\mathrm{NI}}=\frac{1}{2} \rho_{0}\left|\mathbf{u}_{\mathrm{NI}}^{\prime}\right|^{2}
$$

where $\rho_{0}=1025 \mathrm{~kg} \mathrm{~m}^{-3}$. The horizontal energy fluxes in the two wave bands are defined as

$$
\mathbf{F}_{\mathrm{SD}}=\int_{-H}^{0} \mathbf{u}_{\mathrm{SD}}^{\prime} p_{\mathrm{SD}}^{\prime} d z \text { and } \quad \mathbf{F}_{\mathrm{NI}}=\int_{-H}^{0} \mathbf{u}_{\mathrm{NI}}^{\prime} p_{\mathrm{NI}}^{\prime} d z
$$

\section{b. Wentzel-Kramers-Brillouin scaling}

Waves propagating through a nonhomogeneous medium undergo refraction, which changes the waves' properties. In the ocean, internal waves propagating vertically through a varying stratification consequently undergo changes in their amplitude and wavelength. To take this effect into account, velocity measurements can be scaled to the stratification [WentzelKramers-Brillouin (WKB) scaling, introduced in Leaman and Sanford (1975)]. We WKB-scaled the wave velocity using the WOA18 monthly climatology of $N^{2}$ interpolated at the time and location of the measurements. For example, the WKBscaled zonal velocity is

$$
\tilde{u}(t, z)=u(t, z)\left[\frac{N(t, z)}{\int_{-H}^{0} N(t, z) d z}\right]^{-1 / 2} .
$$

WKB scaling enables the comparison of velocity and energy patterns independently of the season, depth and location 


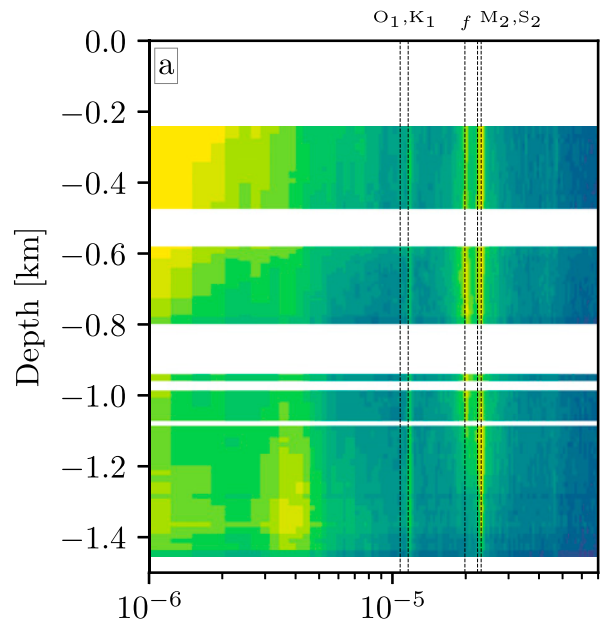

Frequency $[\mathrm{Hz}]$
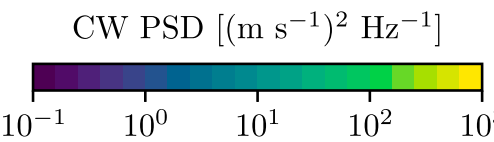

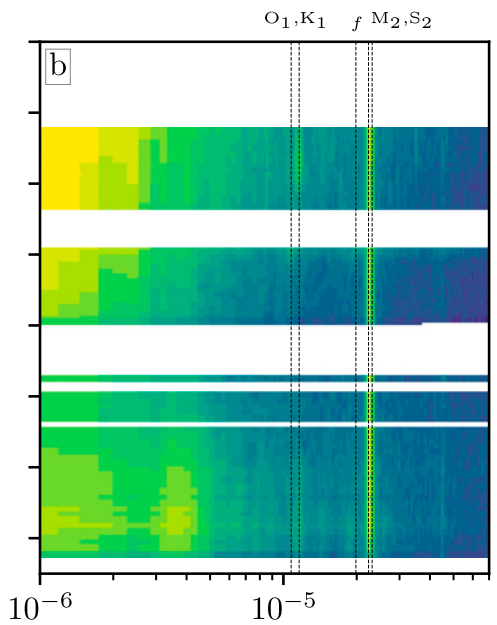

Frequency $[\mathrm{Hz}]$

CCW PSD $\left[\left(\mathrm{m} \mathrm{s}^{-1}\right)^{2} \mathrm{~Hz}^{-1}\right]$

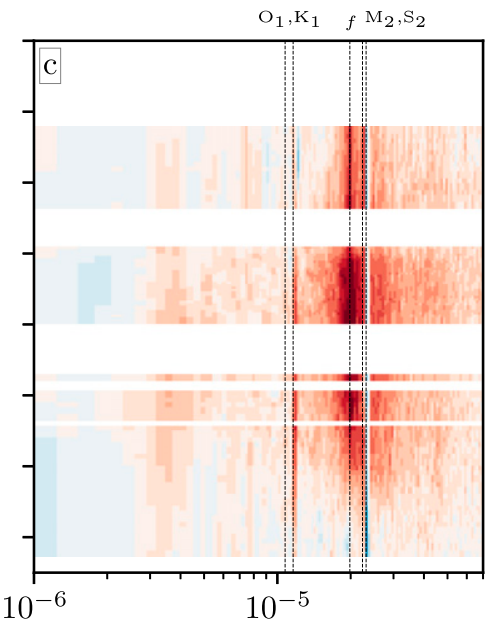

Frequency $[\mathrm{Hz}]$

$\mathrm{CW} / \mathrm{CCW}$

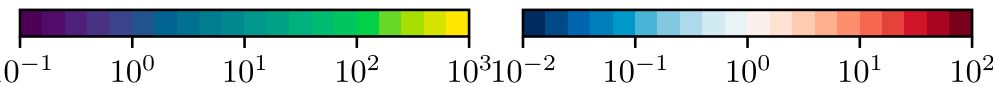

FIG. 2. PSD of (a) clockwise (CW) and (b) counterclockwise (CCW) motions as a function of depth from velocity measurements from mooring RRT. (c) Ratio of the CW PSD to CCW PSD. Vertical dashed lines represent, from left to right, the diurnal tidal frequencies $\mathrm{O}_{1}$ and $\mathrm{K}_{1}$, the inertial frequency $f$, and the semidiurnal tidal frequencies $\mathrm{M}_{2}$ and $\mathrm{S}_{2}$.

(e.g., Alford and Whitmont 2007). In the following, all velocity and energy profiles are WKB-scaled and we omit tildes in notations for convenience.

\section{c. Barotropic-to-baroclinic tidal energy conversion semianalytical model}

In a stratified fluid, the interaction of an oscillating current with a sloping boundary generates internal waves. In the ocean, the barotropic tidal currents slosh to and fro on the underlying seafloor topography to generate internal waves at tidal frequencies, that is, internal, or baroclinic tides. Under the assumptions of small topographic slopes $|\nabla h|$ relative to wave characteristic slopes $\alpha=\sqrt{\left(\omega^{2}-f^{2}\right) /\left(N^{2}-\omega^{2}\right)}$, and small tidal excursions, linear models have been formulated to quantify the barotropic-tobaroclinic energy conversion (e.g., Bell 1975a,b; Nycander 2005; Garrett and Kunze 2007). Here, we use the same formulation of the linear model for barotropic-to-baroclinic tidal energy conversion as in St. Laurent and Garrett (2002) and Vic et al. (2018, 2019).

The energy conversion $C$ reads as

$$
\begin{aligned}
C(K, \theta)= & \frac{1}{2} \rho_{0} \frac{\left[\left(N_{b}^{2}-\omega^{2}\right)\left(\omega^{2}-f^{2}\right)\right]^{1 / 2}}{\omega} \\
& \times\left(u_{e}^{2} \cos ^{2} \theta+v_{e}^{2} \sin ^{2} \theta\right) K \phi(K, \theta),
\end{aligned}
$$

where $N_{b}$ is the buoyancy frequency close to the bottom computed from WOA18; $u_{e}$ and $v_{e}$ are the barotropic tidal velocity amplitude in the direction of the semimajor and semiminor axis of the tidal ellipse, respectively $\left[\left(x_{e}, y_{e}\right)\right.$ coordinate system]; $K=\left(k_{x}^{2}+k_{y}^{2}\right)^{1 / 2}$ is the horizontal wavenumber, with $k_{x}$ and $k_{y}$ being the horizontal wavenumbers in the $\left(x_{e}, y_{e}\right)$ coordinate system; and $\theta=\arctan \left(k_{y} / k_{x}\right)$. The 2D power spectrum of topography, $\phi$, is normalized to satisfy $\int_{0}^{2 \pi} \int_{0}^{\infty} \phi(K, \theta) K d K d \theta=\overline{h^{2}}$, where $\overline{h^{2}}$ is the mean square height of topography.

The conversion into mode $j$ is defined as

$$
C^{j}=\int_{0}^{2 \pi} \int_{K_{j}-\delta K / 2}^{K_{j}+\delta K / 2} C(K, \theta) K d K d \theta,
$$

where $K_{j}$ is the equivalent wavenumber of mode $j$, defined as

$$
K_{j}=\frac{j \pi}{H}\left(\frac{\omega^{2}-f^{2}}{\langle N\rangle^{2}-\omega^{2}}\right)^{1 / 2},
$$

where angle brackets denotes a depth-averaged quantity. The wavenumber interval is $\delta K=K_{2}-K_{1}$. The total energy conversion is thus

$$
C=\int_{0}^{2 \pi} \int_{K_{1}-\delta K / 2}^{\infty} C(K, \theta) K d K d \theta .
$$

We compute $C$ on a $0.25^{\circ}$ grid encompassing the northeast part of the North Atlantic subpolar gyre; $\phi$ is computed at each grid point on a square of seafloor topography extracted from SRTM30_PLUS (Becker et al. 2009), whose side is 2 times the semidiurnal mode- 1 wavelength. Instead of using the tidal currents at the individual tidal frequencies, we define the tidal ellipse parameters at the maximum and minimum of the spring-neap cycle (section $2 \mathrm{~b}$ ), hence we have two independent estimates of energy conversion during spring and neap tides, $C_{s}$ and $C_{n}$. Alternatively, we estimate a continuous time series of tidal energy conversion 


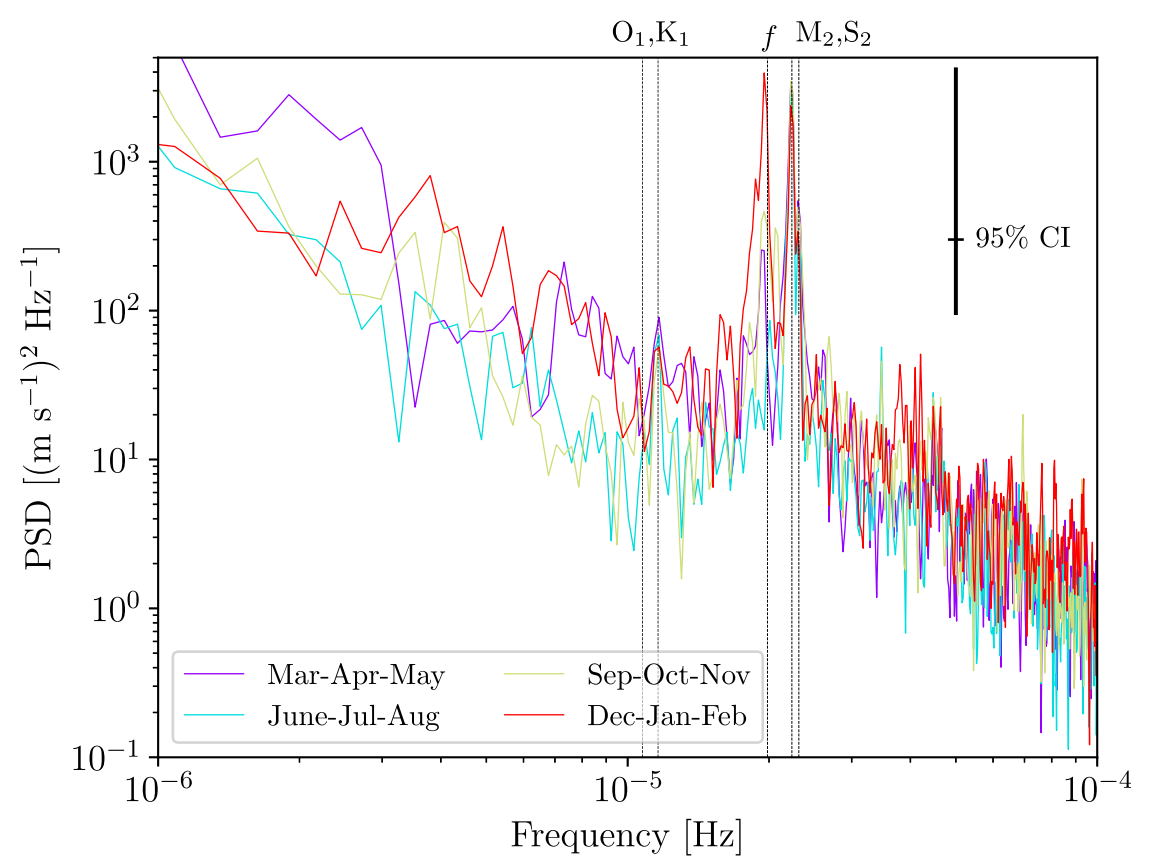

FIG. 3. PSD of clockwise velocity at a mean depth of $258 \mathrm{~m}$ for the seasons from March 2016 to February 2017 (see legend). Velocity measurements are from mooring RRT. Vertical dashed lines represent, from left to right, the diurnal tidal frequencies $\mathrm{O}_{1}$ and $\mathrm{K}_{1}$, the inertial frequency $f$, and the semidiurnal tidal frequencies $\mathrm{M}_{2}$ and $\mathrm{S}_{2}$. The $95 \%$ confidence intervals of the PSDs computed from Welch's PSDs are shown in black.

by multiplying $C_{s}$ with a normalized barotropic tidal kinetic energy time series-this is consistent with Eq. (8), which shows that $C$ is proportional to the squared barotropic tidal currents.

Although the abovementioned assumption of subcritical topography is valid almost everywhere in the area of interest when considering the largest scales of topography, it might not be the case at small scales $(<10 \mathrm{~km})$. We compute the pointwise criticality parameter $\gamma=|\nabla h| / \alpha$ within each topography square, and we adapted the correction proposed in, for example, Green and Nycander (2013) and Vic et al. (2019) based on Nycander (2006):

$$
C=p \frac{C}{{\overline{\gamma_{\mid \gamma>1}}}^{2}}+(1-p) C,
$$

where $p$ is the fraction of grid points at which $\gamma>1$ and $\overline{\gamma_{\mid \gamma>1}}$ is the average $\gamma$ over the domain where it exceeds 1 . Over the ridge, $p=0.4-0.6$ and $\overline{\gamma_{\mid \gamma>1}} \lesssim 2$, which reduces the conversion by a maximum of $40 \%$. Overall, the correction reduces $C$ by only $6 \%$.

\section{d. Wind work on near-inertial motions}

We compute the wind work on near-inertial motions as

$$
W_{\mathrm{NI}}=\boldsymbol{\tau}_{\mathrm{NI}} \cdot \mathbf{u}_{\mathrm{NI}_{s}},
$$

where $\boldsymbol{\tau}_{\mathrm{NI}}$ and $\mathbf{u}_{\mathrm{NI}_{s}}$ are the wind stress and the horizontal surface velocity in the near-inertial band (Flexas et al. 2019). We use the following wind stress definition:

$$
\boldsymbol{\tau}=\rho_{a} C_{D} \mathbf{u}_{r}\left|\mathbf{u}_{r}\right|,
$$

where $\rho_{a}$ is the air density, $C_{D}$ is the drag coefficient (Large and Yeager 2009), and $\mathbf{u}_{r}=\mathbf{u}_{10}-\mathbf{u}_{s}$ is the relative wind speed, defined as the difference between the wind speed at $10 \mathrm{~m}$ above sea level [ $\mathbf{u}_{10}$ (from ERA5)] and the surface velocity in the ocean $\mathbf{u}_{s}$. Because ERA5 is a reanalysis product that does not account for the current feedback effect on the wind stress (Renault et al. 2020), we use the correction in Renault et al. (2016); that is, $\mathbf{u}_{r}=\mathbf{u}_{10}-\left(1-s_{w}\right) \mathbf{u}_{s}$, where $s_{w}=0.3$ is the globally averaged value of the current-wind coupling coefficient (Renault et al. 2020). In practice, for each mooring, we use the surface-most ADCP bin with valid data as a surrogate for $\mathbf{u}_{\mathrm{NI}_{s}}$ and $\mathbf{u}_{s}$ (Silverthorne and Toole 2009; Waterhouse et al. 2018), although we cannot be sure that it is in the mixed layer.

\section{Results}

\section{a. Overview}

In this section, we give an overview of the internal waves' properties, allowing a comparison of internal tides and nearinertial waves, before delving into more details on the phenomenology and mechanisms associated with each wave band.

\section{1) SPECTRAL DENSITY OF HORIZONTAL CURRENTS}

Figure 2 shows the power spectral density (PSD) of clockwise and counterclockwise currents as a function of depth for mooring RRT. PSDs were computed using Welch's method (1024-h segments with half-segment overlap) over the whole 


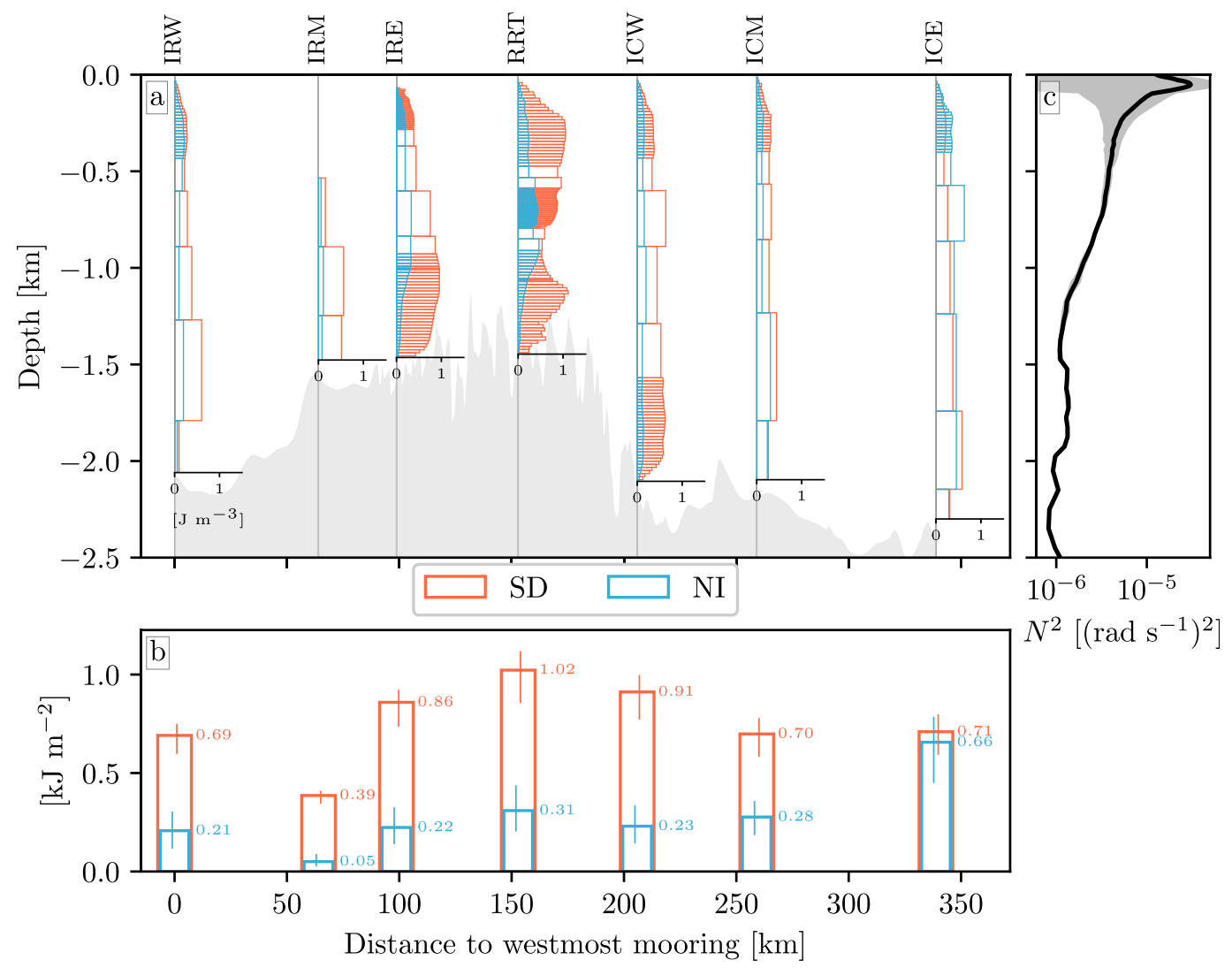

FIG. 4. Time-averaged kinetic energy in the semidiurnal (SD; red) and near-inertial (NI; blue) wave bands for each mooring (a) as a function of depth $\left(\mathrm{J} \mathrm{m}^{-3}\right)$ — each bin accounts for an independent velocity measurement-and (b) depth integrated $\left(\mathrm{kJ} \mathrm{m}^{-2}\right.$ ). Gray shadings in (a) show the bathymetry. Error bars in (b) represent the lower and upper estimates of depth-integrated energy computed from velocity filtered with the bandwidth parameters $c=$ 1.035 (halved bandwidth as compared with the reference parameter $c=1.07$ ) and $c=1.105$ (doubled bandwidth), respectively. (c) Buoyancy frequency $N^{2}$ from WOA18 averaged over the mooring locations. Black line is the annual mean and shaded areas represent the standard deviation from the mean computed from monthly data.

time series of measurements, hence PSDs have some gaps in the water column wherever velocity measurements feature any bad data during the deployment. We choose mooring RRT here to illustrate the time and depth variability because it is the most instrumented, but the picture is consistent along all moorings. Currents show a slightly enhanced variability at the diurnal tidal frequencies $\left(\mathrm{O}_{1}\right.$ and $\left.\mathrm{K}_{1}\right)$ and a more pronounced variability at the semidiurnal tidal frequencies $\left(\mathrm{M}_{2}\right.$ and $\left.\mathrm{S}_{2}\right)$ over the whole column, both in the clockwise and counterclockwise PSDs. In contrast, the inertial variability is only intensified in the clockwise motions (Alford et al. 2016), and is enhanced in the top and middle layers. It smoothly damps with depth and does not reach the bottommost $\sim 200 \mathrm{~m}$ (Fig. 2c). Note that the currents have been WKB-scaled so the damping is not due to a reduced stratification effect. This points toward a surface generation of near-inertial waves by the wind, as opposed to flow-topography interactions.

PSDs of clockwise velocity at an average depth of $258 \mathrm{~m}$ computed from seasonal time series from March 2016 to February 2017 (Welch's method; 1024-h segments with halfsegment overlap) highlight a stark contrast in near-inertial energy levels between winter and summer times (Fig. 3). The highest peak in the near-inertial band is reached in winter (December-February) and is comparable to the semidiurnal peak. While modest peaks are found in spring (March-May) and autumn (September-November), there is no evidence for any near-inertial energy intensification in summer (June-August). This seasonal cycle strengthens the hypothesis that the near-inertial energy is at first order driven by the wind.

\section{2) KinEtiC ENERGY DENSITY}

The vertical structure of the waves' variability inferred from the PSDs is confirmed by the time-mean kinetic energy in the semidiurnal $\left(E_{\mathrm{SD}}\right)$ and near-inertial $\left(E_{\mathrm{NI}}\right)$ bands (Fig. $\left.4 \mathrm{a}\right)$. Variables $E_{\mathrm{SD}}$ and $E_{\mathrm{NI}}$ have similar structures on the vertical, but $E_{\mathrm{SD}}$ is larger than $E_{\mathrm{NI}}$ by a factor of 2-3 for all moorings, except the easternmost one where $E_{\mathrm{SD}}$ and $E_{\mathrm{NI}}$ have similar amplitudes. A striking feature is that the profiles do not exhibit a strong variability with depth, apart from slight local enhancements of $E_{\mathrm{SD}}$ at moorings IRE and RRT. These steady profiles can be explained by the smoothly varying stratification 

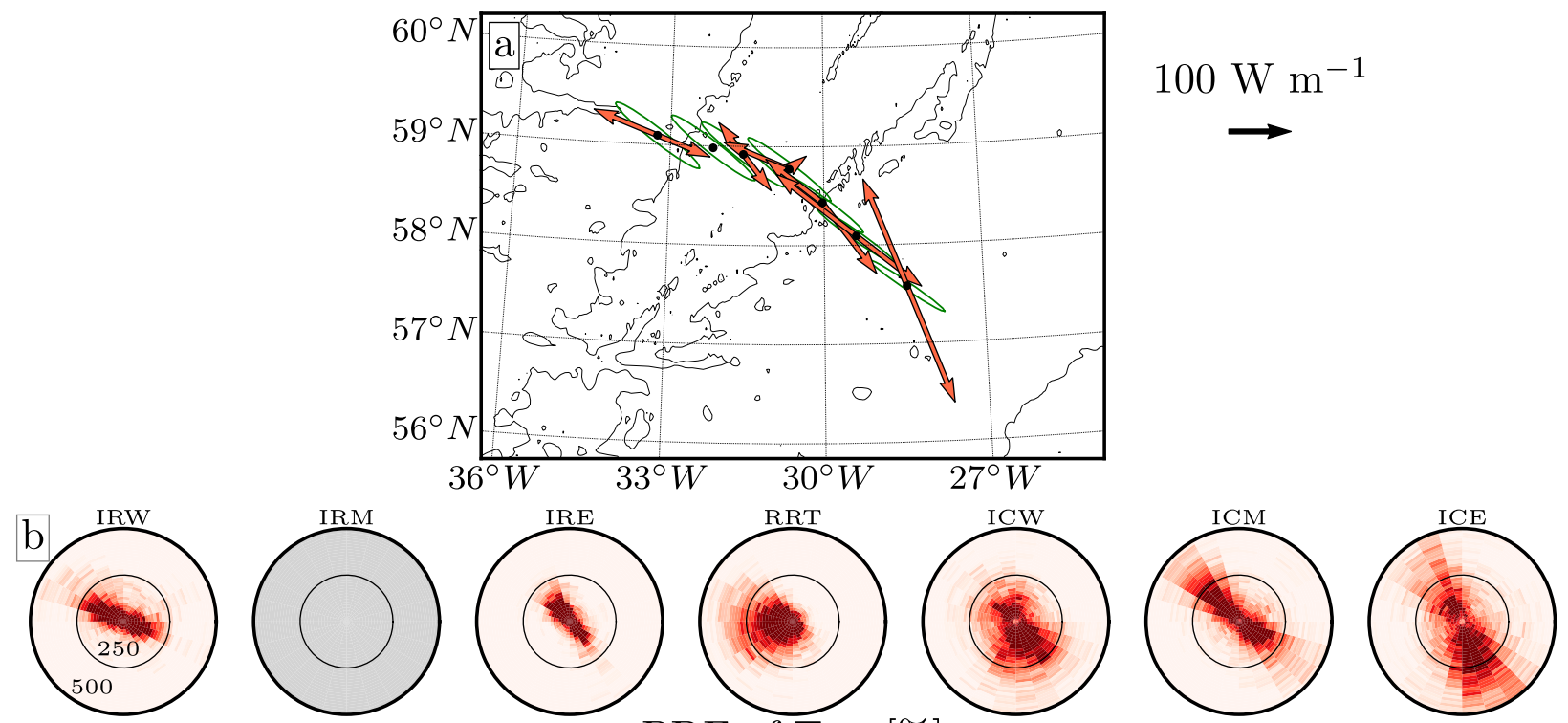

$\mathrm{PDF}$ of $\mathbf{F}_{\mathrm{SD}}[\%]$
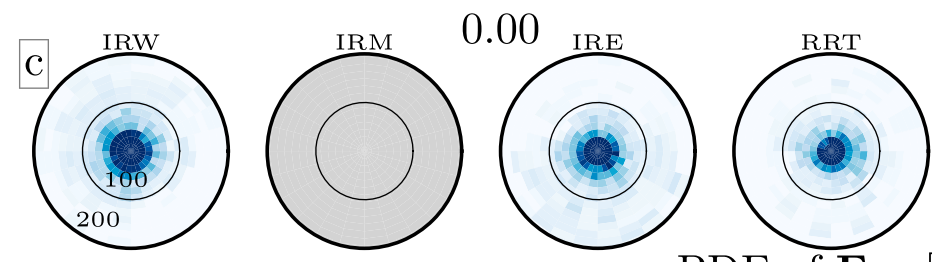

$\mathrm{PDF}$ of $\mathbf{F}_{\mathrm{NI}}[\%]$
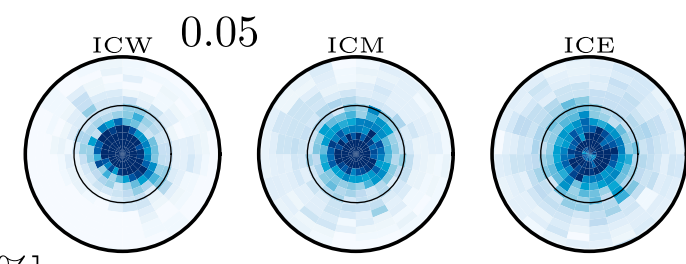

0.0

0.1

FIG. 5. (a) Arrows represent the depth-integrated energy fluxes in the semidiurnal wave band. For each mooring, we identified the angles for which the radially integrated PDF of the SD fluxes [in (b); see below] reach their two maxima. The corresponding two fluxes are represented by the arrows. Green ellipses represent the tidal ellipse during spring tides. Black lines are bathymetry contours $-1,-2$, and $-3 \mathrm{~km}$. Also shown are two-dimensional PDFs of (b) SD energy fluxes and (c) NI energy fluxes. The radial scales are indicated for mooring IRW $\left(\mathrm{W} \mathrm{m}^{-1}\right)$ and are different in (b) and (c).

with depth typical of high latitudes (Fig. 4c), which weakly affects the propagation and possible breaking of the waves, as compared with the more stratified low latitudes (Alford and Whitmont 2007). The energy density decay toward the seafloor occurs over a larger height scale for $E_{\mathrm{NI}}$ compared to $E_{\mathrm{SD}}$, which is compatible with a wind-driven near-inertial wave field. Note that the energy decay toward the surface is due to data gaps, mostly in winter, that reduce the filtered signals in the internal wave-wave bands.

The depth-integrated kinetic energy density in the semidiurnal band $\left\langle E_{\mathrm{SD}}\right\rangle$ features a maximum at the ridge top and decays smoothly on both flanks (Fig. 4b). This cross-ridge variability is qualitatively explained by the geographical variability of the forcing: while nearing the ridge top, the seafloor shallows, hence the barotropic tidal currents increase (by conservation of mass) and the bottom stratification increases. As a consequence, the energy conversion into internal tides increases. Apart from mooring IRM that misses measurements in almost half of the water column, $\left\langle E_{\mathrm{SD}}\right\rangle$ decays away from the ridge at a similar rate on the eastern and western sides.

While the near-inertial kinetic energy density, $\left\langle E_{\mathrm{NI}}\right\rangle$, is almost constant from IRW to ICM, ICE features a two- to threefold increase compared to other moorings. As all moorings experienced statistically similar wind forcing (not shown) and mesoscale eddy dynamics (discussed in section $4 d$ ), reasons for this local maximum remain obscure. ${ }^{1}$

Because of the high latitudes of the study site, the inertial and the semidiurnal frequencies are close to each other, and the spectral peaks of oceanic variables in these wave bands are also close to each other (Fig. 3). This imposes a narrow

\footnotetext{
${ }^{1}$ It is, however, plausible that near-inertial waves generated eastward of the mooring array could have reached ICE with more energy than the other moorings. This is compatible with the observations in winter 2015/16 (Figs. 13k,1).
} 


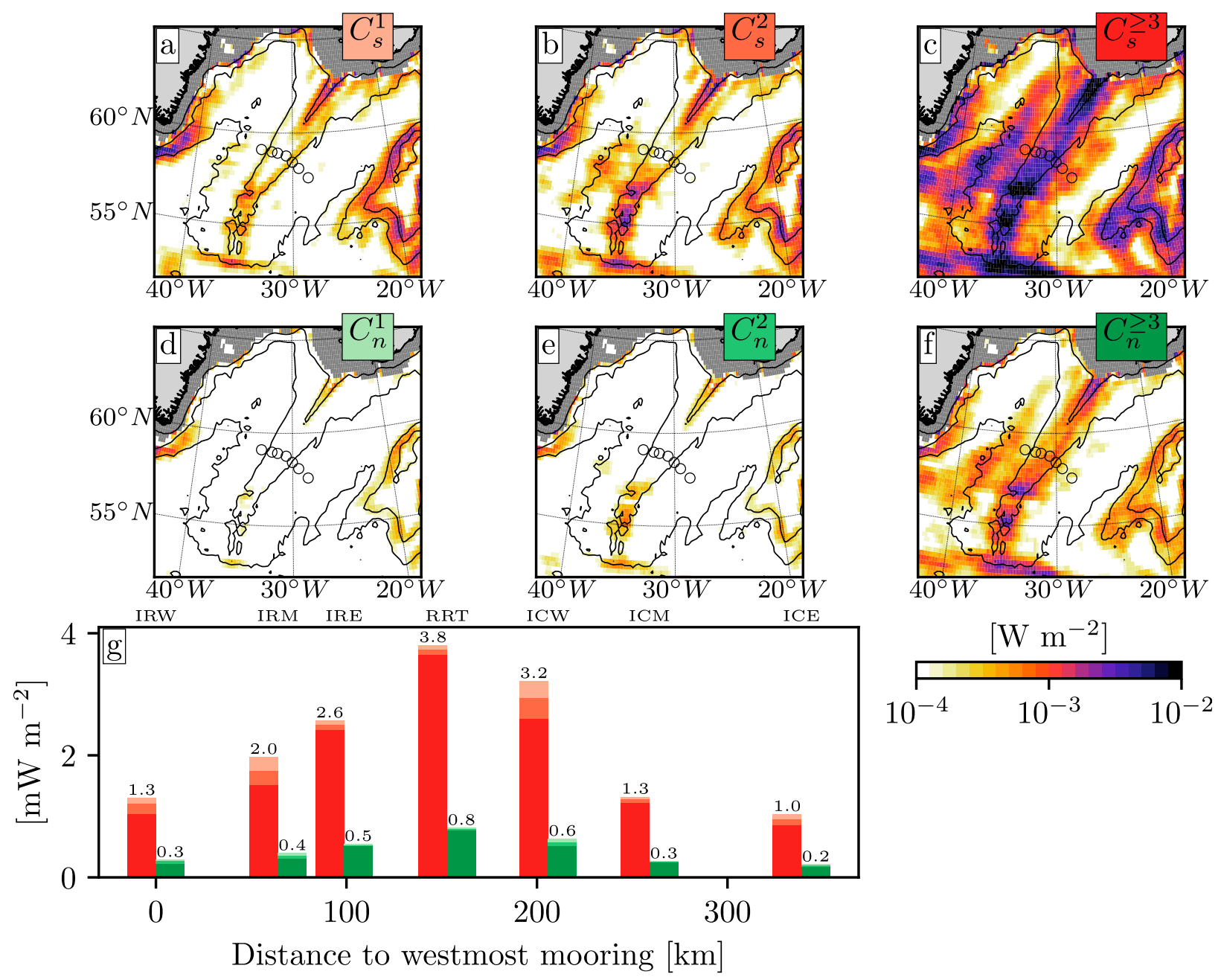

FIG. 6. Barotropic-to-baroclinic tidal energy conversion in mode 1 , mode 2 , and modes $\geq 3$ in (a)-(c) spring tide and (d)-(f) neap tide. Empty circles show the mooring locations, and black lines are bathymetry contours $-1,-2$, and $-3 \mathrm{~km}$. (g) Conversion fields interpolated at the mooring locations; the color code follows the labels in maps.

bandwidth for filtering the near-inertial and the semidiurnal signals, which could potentially lead to underestimate the energy in these wave bands. We tested the sensitivity of the filtered energy to the bandwidth parameter $c$ (set to $1.07)$, by halving $(c=1.035)$ and doubling $(c=1.105)$ the filtering bandwidth. The lower and upper estimates of energy, obtained by halving and doubling the bandwidth, respectively, are shown as error bars in Fig. 4b. In the semidiurnal band, because the spectral peak is very narrow, the energy is overall weakly sensitive to the choice of $c$ : halving the bandwidth decreases the energy by $10 \%-16 \%$ across moorings and doubling it increases the energy by $5 \%-12 \%$ (relative to the values obtained with $c=1.07$ ). On the contrary, in the near-inertial band, because the peak is broader, the energy is more sensitive to $c$ : halving the bandwidth decreases the energy by $31 \%$ to $42 \%$ and doubling it increases the energy by $19 \%$ to $45 \%$, potentially including energy from remote sources. Overall, the narrow filtering bandwidth does not impact qualitatively the results, but we have to keep in mind that it necessarily gives more weight to the local sources of near-inertial forcing.

\section{3) ENERGY FLUXES}

Energy fluxes have contrasted characteristics in the semidiurnal and near-inertial wave bands (Fig. 5). Semidiurnal fluxes have an overall small magnitude $\left[O(100) \mathrm{W} \mathrm{m}^{-1}\right.$; Fig. 5a], as compared with other prominent sites of internal tide generation, for example the Hawaiian Ridge $\left[O(1-10) \mathrm{kW} \mathrm{m}^{-1}\right.$; Merrifield et al. 2001], the Macquarie Ridge $\left(\sim 3 \mathrm{~kW} \mathrm{~m}^{-1}\right.$; Waterhouse et al. 2018), or the Mendocino Escarpment ( $7 \mathrm{~kW} \mathrm{~m}^{-1}$; Althaus et al. 2003). They are strongly polarized in the northwest-southeast direction as revealed by their twodimensional probability density function (PDF; Fig. 5b). They mostly align with the direction of the semimajor axis of the local tidal ellipses (Fig. 5a), which suggests a near-local generation of internal tides.

In contrast to semidiurnal fluxes, near-inertial fluxes are highly variable in direction (Fig. 5c), and have a magnitude that 


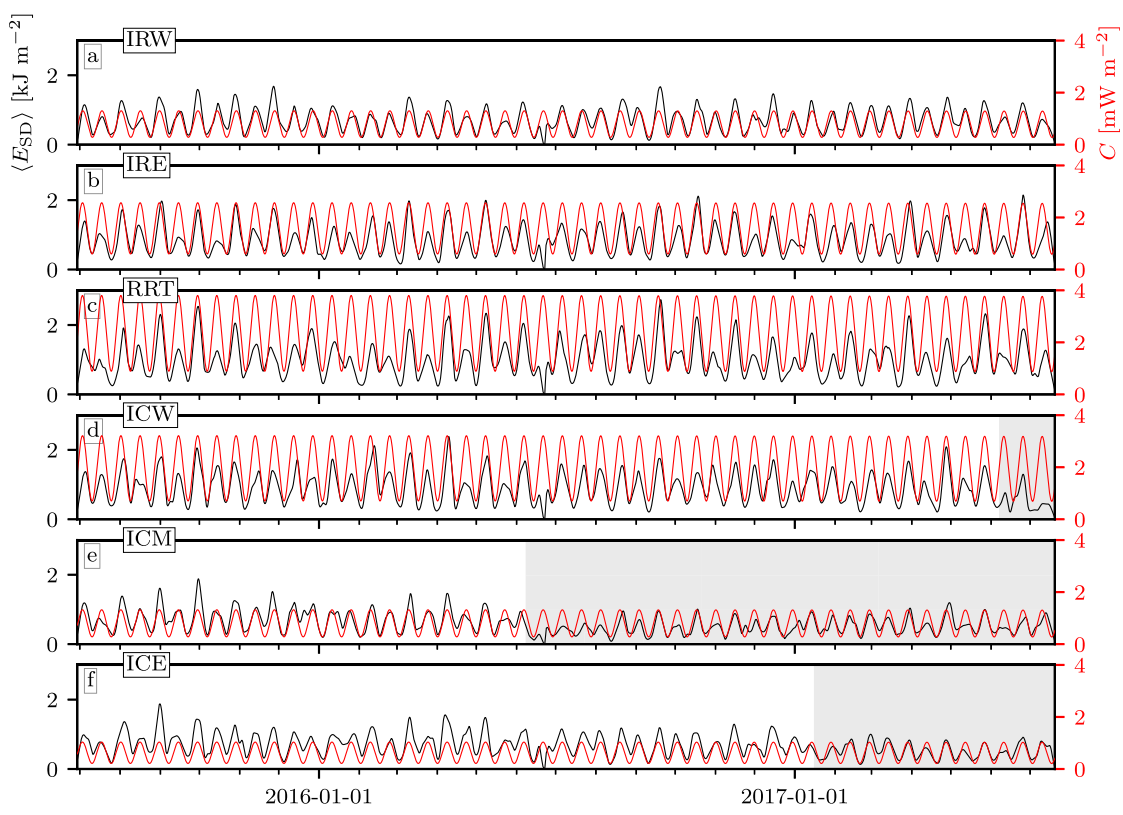

FIG. 7. Time series of depth-integrated semidiurnal kinetic energy $\left\langle E_{\mathrm{SD}}\right\rangle$ (black) and barotropic-to-baroclinic (red) tidal energy conversion for all moorings except IRM. Areas are shaded gray when the uppermost ADCPs stopped recording data.

is smaller by a factor of 2-3. This is notably due to the weaker near-inertial energy density (Fig. 4) and the inherent properties of near-inertial waves, which have a small horizontal group speed (e.g., Alford et al. 2016). Although near-inertial waves are theoretically constrained to travel equatorward, that is, to regions of smaller inertial frequencies, no evidence for such a preferred direction is found here.

\section{b. Internal tides dynamics}

Figure 6 shows maps of barotropic-to-baroclinic tidal energy conversion during spring and neap tides. The regional picture is consistent with global findings: most of the high-mode generation occurs along the ridge, and most of the low-mode generation occurs on the continental slopes (Vic et al. 2019). There is a factor-of-4.3-5.3 increase in energy conversion during spring tides $\left(C_{s}\right.$, Figs. 6a-c) when compared with neap tides $\left(C_{n}\right.$, Figs. 6d-f). This comes from the squared dependence of energy on the barotropic tidal currents [Eq. (8)], which approximately double from neap to spring tides in the area. At the mooring sites, energy conversion is $O(1) \mathrm{mW} \mathrm{m}^{-2}$ (Fig. $6 \mathrm{~g}$ ), within the order of magnitude of typical values over midocean ridges (Vic et al. 2018). It reaches a maximum at the ridge top and decays at a similar rate on both flanks.

Time series of low-pass-filtered $\left\langle E_{\mathrm{SD}}\right\rangle$ ( $0.5 f$ cutoff frequency) display a clear spring-neap variability (Fig. 7). This is consistent with past observations in the surroundings of internal tide generation sites (e.g., Alford and Zhao 2007). Furthermore, here, energy and conversion are remarkably in phase with regard to the spring-neap variability for all sites (Fig. 7 and associated two-dimensional PDFs in Fig. 8). This phase locking strongly supports the idea that the dominant source of semidiurnal energy comes from the ridge. Indeed, if the energy levels were dominated by remote sources-e.g., Rockall Plateau or Greenland slopes, which generate lowmode waves (Figs. 6a,b) $-\left\langle E_{\mathrm{SD}}\right\rangle$ would have lagged behind $C$ by at least 6 days, assuming a low-mode group speed of $\sim 1 \mathrm{~m} \mathrm{~s}^{-1}$ (Fig. 1 in Rainville and Pinkel 2006) and a distance of $\sim 500 \mathrm{~km}$ from the potential sources to the mooring sites (Fig. 1).

At each mooring site, the energy density is linearly tight to the local energy conversion through a coefficient $\tau$ that has units of time (Fig. 8). Coefficient $\tau$ is estimated as the linear regression coefficient of $\left\langle E_{\mathrm{SD}}\right\rangle$ versus $C$ and can be interpreted as a replenishment time scale: for a given energy conversion, $\tau$ represents the time the conversion needs to operate to reach the observed energy level. If the local energy level is fully explained by a local source, ${ }^{2}$ then $\tau$ would be strictly the same between all sites, as the conversion and the medium (stratification and depth) have the same characteristics. However, $\tau$ displays a marked cross-ridge variability. In places where energy conversion is the largest, that is, on the ridge top (moorings IRE, RRT and ICW), $\tau$ is approximately 4-5 days. In contrast, where the conversion is smaller, that is, on the ridge flanks (moorings IRW, ICM and ICE), $\tau$ is approximately 79 days. Our interpretation is as follows. On the ridge top, $\tau$ is small relative to the spring-neap cycle (14.9 days), which is coherent with $C$ and $\left\langle E_{\mathrm{SD}}\right\rangle$ being in phase, and with a locally driven energy level. On the other hand, on the ridge flanks, $\tau$ is roughly equal to onehalf of the spring-neap period. It means that, with a spring-tide forcing, it takes one-half of a spring-neap period for the energy to

\footnotetext{
${ }^{2}$ This assumes a one-dimensional problem in which the waves carry energy vertically.
} 

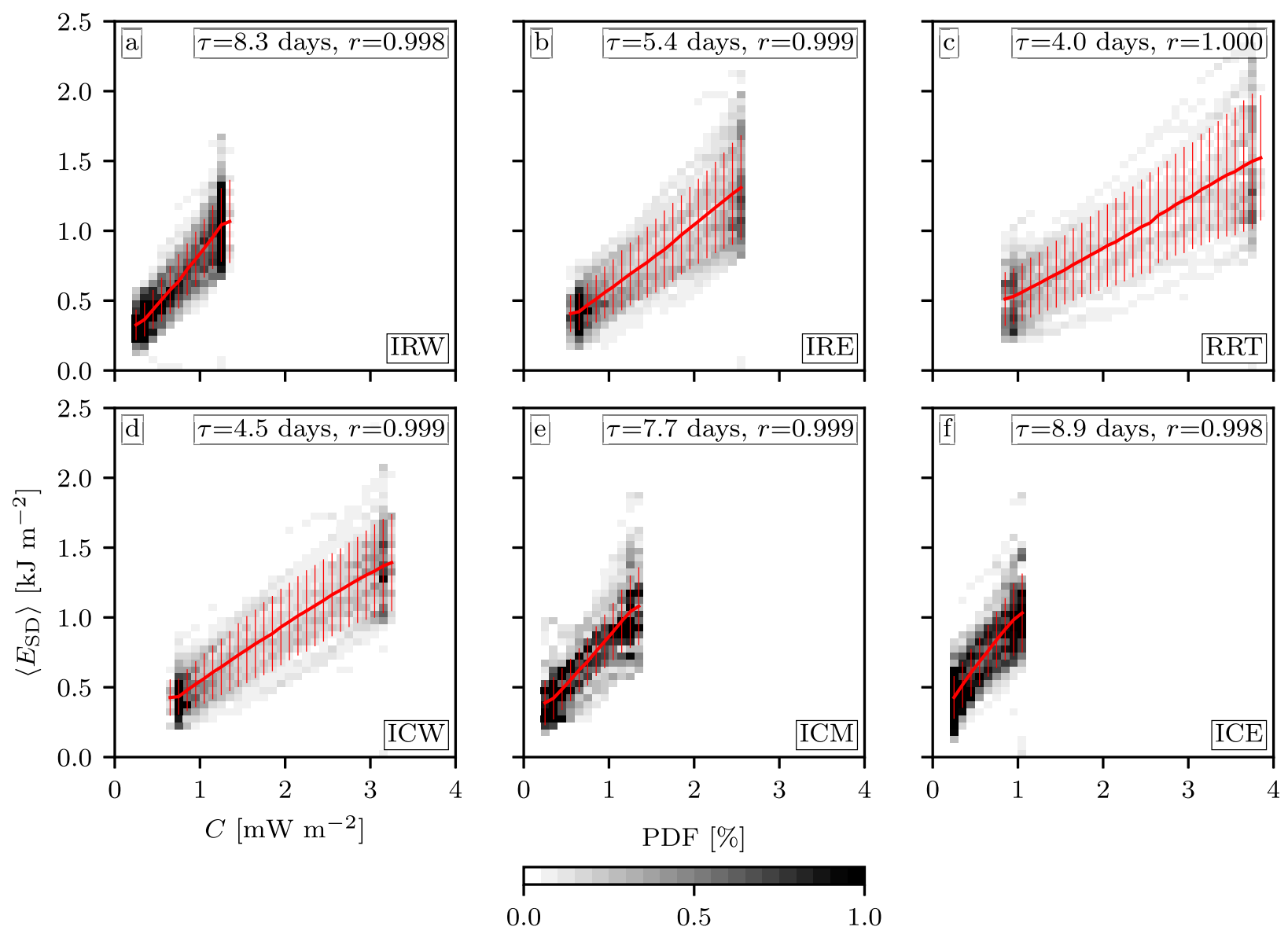

FIG. 8. Two-dimensional PDFs of barotropic-to-baroclinic tidal energy conversion $C$ vs depth-integrated semidiurnal kinetic energy $\left\langle E_{\mathrm{SD}}\right\rangle$ for all moorings except IRM. Data are from the shading-free areas of Fig. 7. Red lines are the mean and standard deviation of $\left\langle E_{\mathrm{SD}}\right\rangle$ per conversion bin. Regression coefficients on binned data $\tau$ have units of a time scale and are given in days for each panel as well as correlation coefficients $r$.

reach its peak. So, if the dynamics were fully local, $C$ and $\left\langle E_{\mathrm{SD}}\right\rangle$ would have been in opposite phase. Because $C$ and $\left\langle E_{\mathrm{SD}}\right\rangle$ are in phase on the ridge flanks, the local energy level might be partially fed by neighboring sources, likely localized on the ridge top (Fig. 6).

This view is supported by the time-averaged cross-ridge structure of $\left\langle E_{\mathrm{SD}}\right\rangle$ (Fig. $4 \mathrm{~b}$ ) versus $C_{s}$ and $C_{n}$ (Fig. 6g). While there is a gentle cross-ridge decay of $\left\langle E_{\mathrm{SD}}\right\rangle$ (by $\sim 30 \%$ ), $C_{s}$ and $C_{n}$ decay more sharply (by $\sim 70 \%-80 \%$ ). Hence, energy must leak away from the ridge top to feed the flanks and help reach the observed energy levels. Note that the cross-ridge energy redistribution is also consistent with the polarized semidiurnal energy fluxes $\mathbf{F}_{\mathrm{SD}}$ (Figs. 5a,b).

Interestingly, only the top-ridge fluxes, derived from moorings RRT and ICW, show some significant variability at the spring-neap frequency (Fig. 9a, PSDs in Fig. 9 are computed using Welch's method, with 6144-h segments and half-segment

\footnotetext{
${ }^{3}$ We unwrapped the phase time series using the numpy programming software's function "unwrap" to avoid absolute jumps between 0 and $2 \pi$.
}

overlap $^{3}$ ) and is phase-locked to the spring-neap cycle of energy conversion (not shown). The fluxes' spring-neap variability in other places is much weaker, both for their magnitude (Fig. 9a) and direction (Fig. 9b). This suggests that internal tides must be largely scattered by mesoscale turbulence and seafloor topography (e.g., Rainville and Pinkel 2006; Lahaye and Llewellyn Smith 2020).

\section{c. Wind generation of near-inertial waves}

In this section we focus on mooring RRT, which has the best sampling resolution in the vertical direction, but the picture is similar in other mooring data. The North Atlantic subpolar gyre features a strong atmospheric seasonal cycle, with low pressure systems generating strong winds in winter (Fig. 10a). The nearinertial component of the wind follows this cycle with a marked year-to-year variability (Fig. 10a), which generates a winter intensification of the work done by the wind to near-inertial motions, $W_{\mathrm{NI}}$ [Eq. (13) and Fig. 10b]. Because the moorings were not equipped with thermistors at depths shallower than $300 \mathrm{~m}$, we were not able to compute the mixed layer depth. Thus, we made use of monthly WOA18 density data to 

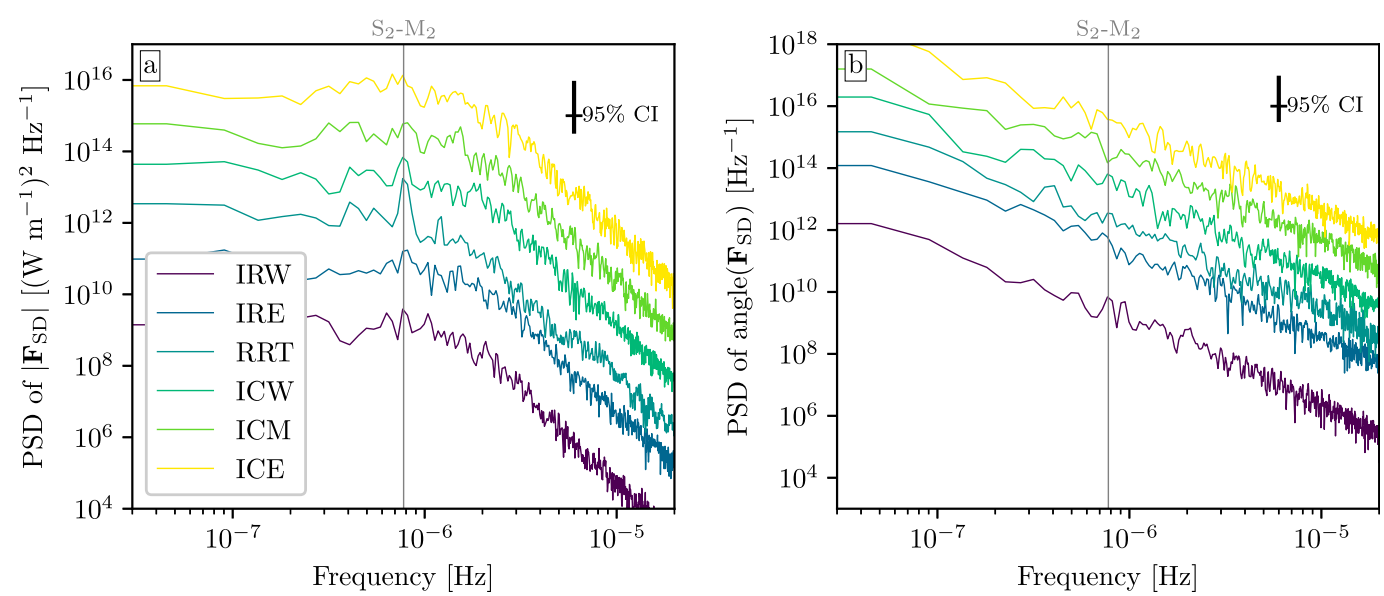

FIG. 9. Power spectral density of (a) the magnitude and (b) angle of semidiurnal energy fluxes computed from each mooring data except IRM. Each PSD is offset by a decade for visual purposes. The gray line shows the frequency of the spring-neap cycle, i.e., the difference between the $S_{2}$ and the $M_{2}$ tidal frequencies. The $95 \%$ confidence intervals of the PSDs computed from Welch's PSDs are shown in black.

compute the mixed layer depth following a criterion of $0.03 \mathrm{~kg} \mathrm{~m}^{-3}$ density jump from 10 -m density (de Boyer Montégut et al. 2004). Near-inertial energy in the mixed layer, $\left\langle E_{\mathrm{NI}}\right\rangle_{\mathrm{ML}}$, closely follows $W_{\mathrm{NI}}$ (Fig. 10b). Their magnitude is proportional, with a lower $\left\langle E_{\mathrm{NI}}\right\rangle_{\mathrm{ML}}$ in the first winter associated with lower $W_{\mathrm{NI}}$, as compared with the second winter. There is a lag of 4.5 days between the maxima of $W_{\mathrm{NI}}$ and $\left\langle E_{\mathrm{NI}}\right\rangle_{\mathrm{ML}}$ (maximum of lagged correlation).

The depth-integrated near-inertial energy $\left\langle E_{\mathrm{NI}}\right\rangle$ also follows $W_{\mathrm{NI}}$, but the peaks seem more diffuse, probably due to the contribution of remotely generated waves that are out of phase with the local forcing. The lag between the maxima of the local forcing and $\left\langle E_{\mathrm{NI}}\right\rangle$ is of 9.1 days.

The ratio of the local forcing, which has units of a flux, to the energy density, gives a replenishment time scale (Alford and Whitmont 2007). In analogy with internal tide dynamics, this can be interpreted as the typical time energy takes to propagate in the local water column. Linear regressions on binned PDFs of $W_{\mathrm{NI}}$ versus $\left\langle E_{\mathrm{NI}}\right\rangle_{\mathrm{ML}}$ (Fig. 11a) and $\left\langle E_{\mathrm{NI}}\right\rangle$ (Fig. 11b) give replenishment time scales of 3.5-3.9 days and 13-15 days, respectively. The replenishment time scale relative to depthintegrated energy is within the bounds of the global study of
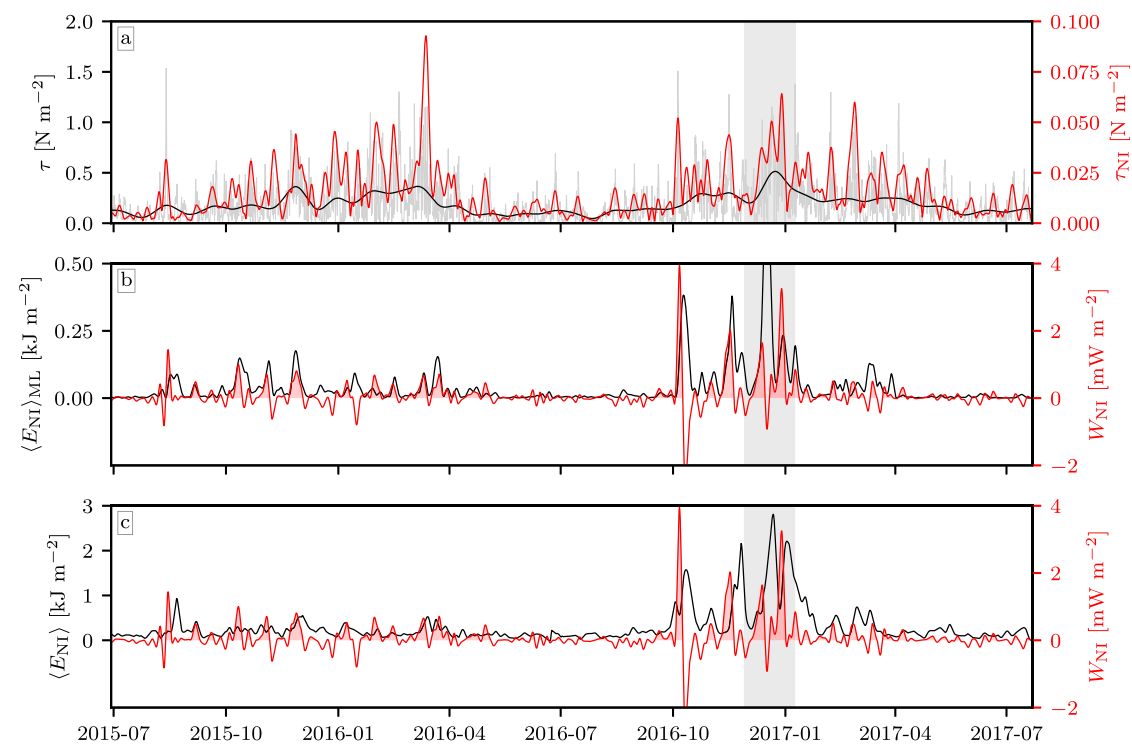

FIG. 10. (a) Time series of raw (gray) and low-pass-filtered (black) wind stress from ERA5 $\tau$ and its near-inertial component $\tau_{\mathrm{NI}}$ (red). Time series of near-inertial kinetic energy (b) averaged over the mixed layer $\left\langle E_{\mathrm{NI}}\right\rangle_{\mathrm{ML}}$ and (c) depth integrated $\left\langle E_{\mathrm{NI}}\right\rangle$. Red lines in (b) and (c) show the wind work on near-inertial motions $F_{\mathrm{NI}}$. Data are from mooring RRT. 


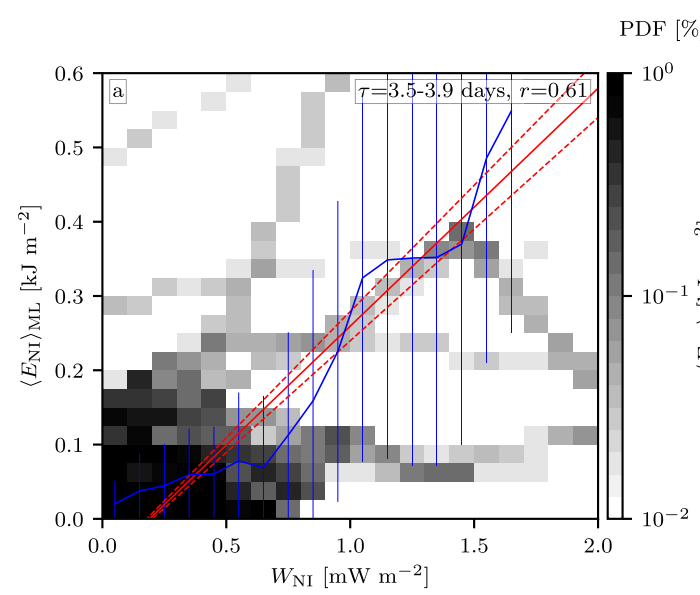

PDF $[\%]$

PDF [\%]

FIG. 11. Two-dimensional PDFs of wind work on near-inertial motions $W_{\mathrm{NI}}$ vs near-inertial kinetic energy (a) averaged over the mixed layer $\left\langle E_{\mathrm{NI}}\right\rangle_{\mathrm{ML}}$ and (b) depth integrated $\left\langle E_{\mathrm{NI}}\right\rangle$. Blue lines are the mean and standard deviation of near-inertial kinetic energy per wind work bin. Red plain lines are the linear regressions from the binned data, and red dashed lines are the $95 \%$ confidence interval on the regression coefficients. Regression coefficients have units of a time scale and are given in days for each panel (95\% confidence limits). Data are from mooring RRT.

Alford and Whitmont (2007) with regard to the $55^{\circ}-65^{\circ}$ latitude band in winter (their Fig. 7). Note, however, that the bin averages seem to be constrained by a few individual events characterized by a strong wind forcing and a strong near-inertial response, and we would need longer observations to get more robust estimates of replenishment time scales. Overall, the close relationship between the local forcing by the wind and the near-inertial energy density strongly supports that the wind is the main forcing fueling this energy reservoir. This local forcing is also consistent with the relative lack of a preferred direction of the fluxes, as the waves would not have reached their turning latitude. ${ }^{4}$

Figure 12 offers a closer look at near-inertial energy propagation during a winter storm event (gray shadings in Figs. 10a-c). After a few days of intensifying winds, a burst of near-inertial energy propagates downward in the water column. The vertical group speed is estimated at $c_{g}$ of approximately $-0.44 \times 10^{-3} \mathrm{~m} \mathrm{~s}^{-1}$. The vertical phase speed is estimated in connecting constant-phase velocity points as function of depth and is $c_{\phi} \sim 5.56 \times 10^{-3} \mathrm{~m} \mathrm{~s}^{-1}$. Combining the expressions for near-inertial group speed and phase speed (Alford et al. 2016) yields a secondorder equation for the vertical wavenumber $m$ that reads as $c_{\phi}^{2} m^{2}-2 c_{g} f m-f^{2}=0$. An assumption that the wave propagates downward gives $m \sim 2 \pi / 259 \mathrm{~m}$. Then, using the dispersion relation and making use of a climatological stratification (Fig. 12) allows us to estimate the horizontal wavenumber as $\sim 2 \pi / 11 \mathrm{~km}$ and the frequency as $1.08 f$. This slightly superinertial frequency is consistent with the observed vertical propagation (pure inertial motions are horizontal). In more general terms, as discussed in the next section, near-inertial waves are influenced by background motions that shift their intrinsic frequency, so this is not

\footnotetext{
${ }^{4}$ The mesoscales also play a role in shifting the frequency of the waves and widen the range of directions of propagation allowed but we could not quantify this effect.
}

uncommon to reconstruct wave signals spanning a wide wave band (e.g., Le Boyer et al. 2020).

\section{d. Testing the near-inertial chimney hypothesis}

Seminal work of Kunze (1985) highlighted how the properties and propagation of near-inertial waves were influenced by the geostrophic background field. Specifically, the propagation of the waves is influenced by the effective Coriolis frequency, $f_{\text {eff }}=f+(\zeta / 2)$, where $\zeta=\partial_{x} v-\partial_{y} u$ is the relative vorticity of the background flow. In the Northern Hemisphere, negative (positive) relative vorticity shifts the effective Coriolis frequency toward smaller (larger) values, increasing (decreasing) the wave bandwidth of existence of internal waves. Ray-tracing experiments, observations, and numerical models confirmed that regions of anticyclonic vorticity were more prone to trap near-inertial waves (e.g., Kunze et al. 1995; Lee and Niiler 1998; Joyce et al. 2013; Jouanno et al. 2016; Fer et al. 2018; Asselin and Young 2020; FernándezCastro et al. 2020).

We explored this tendency in analyzing our observations of near-inertial kinetic energy along with collocated relative vorticity computed from altimetry-derived geostrophic currents $\zeta_{g}$ (section $2 \mathrm{~d}$ and Fig. 13). Visual inspection of the time series of $E_{\mathrm{NI}},\left\langle E_{\mathrm{NI}}\right\rangle$, and $\zeta_{g}$ nondimensionalized by $f$ at each mooring site suggests that the near-inertial energy is larger at depths when $\zeta_{g} / f<0$ (For example, during winter 2016-17; Figs. 13c,d). This is especially true in periods of strong wind forcing, which occur on subseasonal time scales (Fig. 10). The enhancement of near-inertial energy in anticyclonic structures is confirmed by the two-dimensional histogram of $\left\langle E_{\mathrm{NI}}\right\rangle$ versus $\zeta_{g} / f$ gathering all mooring data (Fig. 14a). Linear regression on binned data shows a correlation coefficient of -0.83 with a clear tendency for near-inertial energy to be enhanced in anticyclonic structures. The linear tendency is also consistent with the findings of Whalen et al. (2018) that report enhanced 

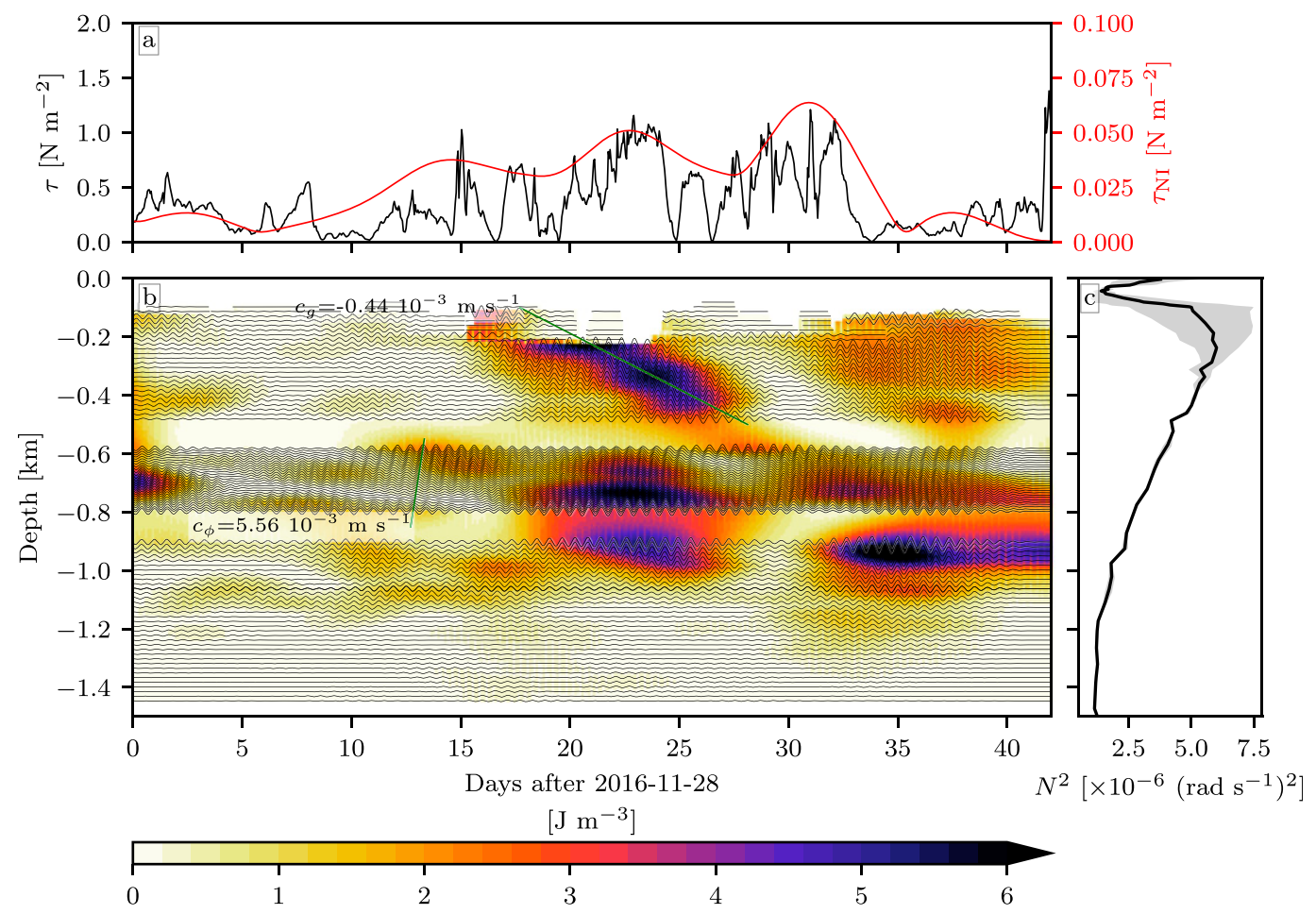

FIG. 12. (a) Time series of wind stress (black) and its near-inertial component over the time interval shaded gray in Fig. 10 (red). (b) Near-inertial kinetic energy as a function of depth and time is in color, and near-inertial zonal velocity at the mean instruments' depths are represented in black lines. Estimates of group speed $c_{g}$ and phase speed $c_{\phi}$ are given. (c) Mean stratification from the monthly WOA climatology at the mooring location over the time window. Gray shading is bounded by the lowest and highest values over the time window. Data are from mooring RRT.

wind-driven mixing in regions of strong mesoscale turbulence, that is, where $\left|\zeta_{g} / f\right|$ reaches high values.

Figure 14b shows the 10th, 50th, and 90th percentiles per 100-m depth bins of $E_{\mathrm{NI}}$ in regions of negative and positive vorticity, labeled $E_{\mathrm{NI}_{\mid \xi_{g}<0}}$ and $E_{\mathrm{NI}_{\mid \xi_{g}>0}}$. While there is not much difference between the 10 th and 50 th percentiles, i.e., where near-inertial is weak, the area between the 50th and the 90th percentiles is much larger in anticyclonic regions in the 0-1000-m depth range. This confirms the preference of near-inertial energy to be funneled down in anticyclonic regions ("near-inertial chimney"; Lee and Niiler 1998).

\section{Summary and discussion}

Using an array of seven moorings deployed for more than 2 years over the Reykjanes Ridge, we documented the life cycle of semidiurnal and near-inertial waves. Results can be summarized as follows:

- Kinetic energy in the semidiurnal band is almost constant on the vertical. Depth-averaged, it reaches $1 \mathrm{~kJ} \mathrm{~m}^{-2}$ at the ridge top and smoothly decreases by $30 \%$ over $150-200 \mathrm{~km}$ to the ridge flanks. This cross-ridge decay is more gradual than the cross-ridge attenuation of the local barotropic-to-baroclinic energy conversion $\left(1.0-3.8 \mathrm{~mW} \mathrm{~m}^{-2}\right.$ in spring tides and
$0.3-0.8 \mathrm{~mW} \mathrm{~m}^{-2}$ in neap tides), which shows a decrease of $70 \%-80 \%$ over the same distance. This suggests that energy on the ridge flanks partially comes from neighboring sources, likely located on the ridge top, where conversion is higher. There is a remarkable phase locking and linear relationship between energy density and energy conversion at the springneap cycle, qualitatively suggesting that the bulk of the forcing is local. The energy-to-conversion ratio for each mooring gives replenishment time scales of 4-5 days on the ridge top versus 7-9 days on the flanks.

- Tidal energy fluxes are low overall $\left[O(0.1) \mathrm{kW} \mathrm{m}^{-1}\right]$, due to a small energy conversion into low modes over the ridge, which usually account for the bulk of the energy flux. They are strongly polarized in the cross-ridge direction, consistent with an energy redistribution from the top to the flanks.

- The near-inertial kinetic energy is smaller than the semidiurnal kinetic energy by a factor of $2-3$, but is much more variable in time. It has an almost constant vertical structure with a decay toward the seafloor below $1 \mathrm{~km}$ depth. It shows a clear seasonal cycle, with a winter intensification and subseasonal peaks corresponding to burst of local wind forcing. The ratio of depth-integrated energy to wind work gives replenishment time scales of 13-15 days, supporting that the wind is the major driver of the (sub) seasonal variability. 


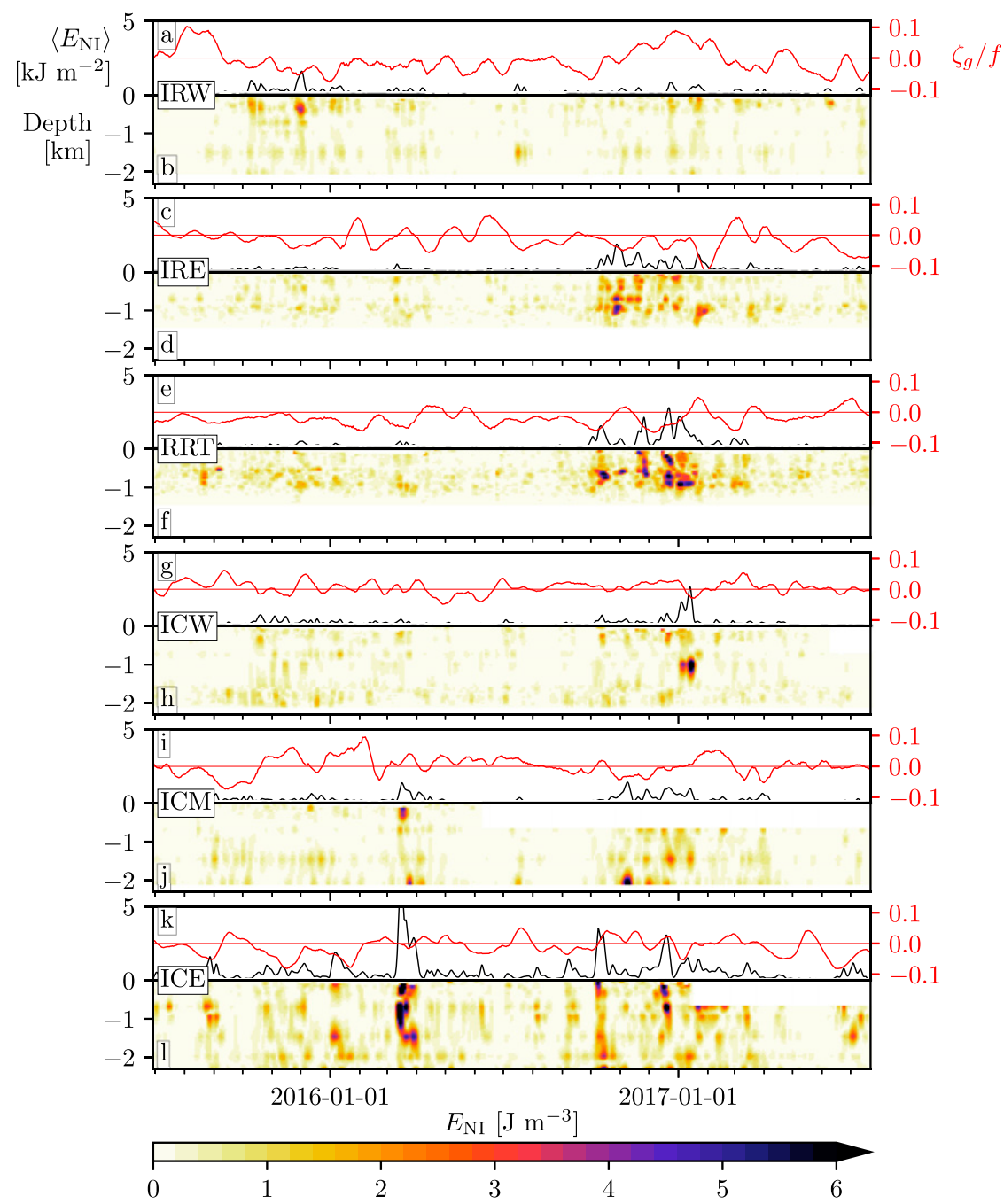

FIG. 13. Time series of depth-integrated near-inertial kinetic energy $\left\langle E_{\mathrm{NI}}\right\rangle$ (black curves) and relative vorticity normalized by the local Coriolis frequency $\zeta_{g} / f$ (red lines), computed from altimetry, and depth-dependent near-inertial kinetic energy $E_{\mathrm{NI}}$ (color shading). Panels are grouped by moorings from west to east: (a),(b) IRW; (c),(d) IRE; (e),(f) RRT; (g),(h) ICW; (i),(j) ICM; and (k),(l) ICE. IRM-derived fields are not shown because of the lack of data in the upper water column.

- Depth-integrated near-inertial energy fluxes are small $\left(<0.1 \mathrm{~kW} \mathrm{~m}^{-1}\right)$ and are not oriented in any particular direction.

- The mooring data nicely illustrate the near-inertial energy intensification in anticyclonic structures that has been theorized and numerically modeled. This property is essentially highlighted for high levels of near-inertial energy, following strong wind forcing, and in the upper $1 \mathrm{~km}$ of the water column.

The strong spring-neap variability of energy conversion and energy density in the semidiurnal band likely has implications for energy dissipation and mixing. To gain insights on the variability of tidally driven energy dissipation, we consider a linear equation for the evolution of energy density:

$$
\frac{\partial E_{\mathrm{SD}}}{\partial t}=\nabla \cdot \mathbf{F}_{\mathrm{SD}}+C-\varepsilon
$$

where $\varepsilon$ is the turbulent energy dissipation. As demonstrated in section $4 \mathrm{~b}$, energy density is linearly dependent on energy conversion, $E_{\mathrm{SD}} \sim \tau C$. In addition, we assume that $C$ can be written as $C=C_{0}+C_{1} \cos (\Omega t)$, where $\Omega$ is the spring-neap frequency, $C_{0}=0.5\left(C_{s}+C_{n}\right)$, and $C_{1}=0.5\left(C_{s}-C_{n}\right)$. Equation (15) thus yields the following expression for energy dissipation:

$$
\varepsilon=C_{0}+C_{1}\left[1+(\Omega \tau)^{2}\right]^{1 / 2} \cos (\Omega t-\phi)+\nabla \cdot \mathbf{F}_{\mathrm{SD}},
$$

with $\phi=\arctan (\Omega \tau)$. It is tempting to make the assumption that the energy convergence/divergence, $\nabla \cdot \mathbf{F}_{\mathrm{SD}}$, can be neglected. In fact, observations show that the tidal energy 


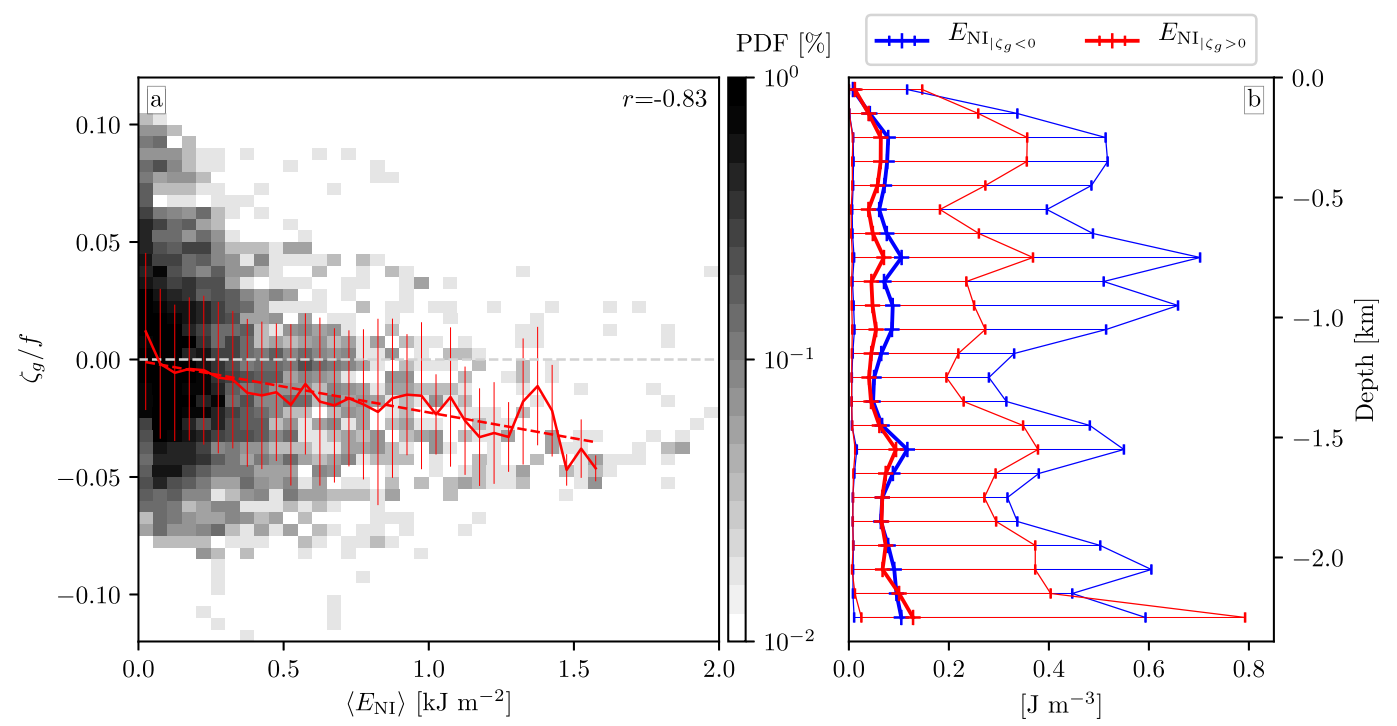

FIG. 14. (a) Two-dimensional PDF of depth-integrated near-inertial kinetic energy $\left\langle E_{\mathrm{NI}}\right\rangle$ and relative vorticity normalized by the local Coriolis frequency $\zeta_{g} / f$. The red thick line represents the averaged $\zeta_{g} / f \operatorname{per}\left\langle E_{\mathrm{NI}}\right\rangle$ bin, and error bars are the standard deviation from the mean. The red dashed line shows the linear regression on these data, which has a regression coefficient of $r=-0.83$. (b) Time-averaged composite profiles of near-inertial kinetic energy for positive (red) and negative (blue) vorticity, $E_{\mathrm{NI}_{\left.\left.\right|_{3}\right\rangle_{0}}}$ and $E_{\mathrm{NI}_{\zeta_{0}<0}}$, respectively. For each 100-m depth bin, the 10th (thin line), 50th (thick line), and 90th (thin line) percentiles are represented. Data from all moorings have been used to produce these plots.

fluxes have a small amplitude and little cross-ridge variability. Based on Fig. 5a, a ballpark estimate of the time-averaged energy divergence gives $\nabla \cdot \mathbf{F}_{\mathrm{SD}} \sim 10 \mathrm{~W} \mathrm{~m}^{-1}(100 \mathrm{~km})^{-1} \sim 0.1 \mathrm{~mW} \mathrm{~m}^{-2}$, which is an order of magnitude smaller than typical energy conversion, at least during most of the spring-neap cycle (Figs. 7 and $6 \mathrm{~g}$ for the exact conversion during spring and neap tides). If we make this assumption, Eq. (16), freed from $\nabla \cdot \mathbf{F}_{\mathrm{SD}}$, highlights several properties of energy dissipation. First, at every location on the ridge, the time-average dissipation over a spring-neap cycle is equal to the mean of the spring-tide conversion and the neap-tide conversion. This is supported by the domination of high-mode internal tides generated on the ridge (Fig. 6), which are prone to rapid breaking. Second, the variability in $\varepsilon$ stems from the variability of $\tau$, which depends on the distance from the ridge top. Near the ridge top, $\tau \ll 1 / \Omega$, hence the amplification factor $[1+$ $\left.(\Omega \tau)^{2}\right]^{1 / 2} \rightarrow 1$ and $\phi \rightarrow \Omega \tau$. As such, $\varepsilon$ converges to $C$ with a phase lag of $\tau$. On the ridge flanks, $\tau$ increases and the amplification factor departs from unity, leading to a stronger energy dissipation than the local conversion. This is consistent with an energy redistribution from neighboring sources, which also means that $\nabla \cdot \mathbf{F}_{\mathrm{SD}}$ could not be neglected through the whole spring-neap cycle.

This conceptual model allows us to put some bounds on energy dissipation and to highlight its natural spring-neap variability, which has been observed (Klymak et al. 2006; Clément et al. 2017; Vic et al. 2018), but is not taken into account in current parameterizations of tidal mixing. However, a caveat from our analysis is that we could not confirm that the energy divergence is negligible over the whole spring-neap cycle. Unfortunately, the time-dependent energy divergence could not be estimated accurately from the present mooring array, since the moorings are too distant from each other and the time-dependent fluxes are very variable in magnitude and direction (Fig. 9). Concomitant and continuous measurements of $E_{\mathrm{SD}}$ and $\nabla \cdot \mathbf{F}_{\mathrm{SD}}$ (and if possible, $\varepsilon$ ) would be necessary to test quantitatively this simple model.

The role of near-inertial waves in mixing the ocean is still unclear. Our observations show that near-inertial energy varies over short time scales, with sudden increases tight to local forcing. The median level of near-inertial energy is almost constant on the vertical but its 90th percentile is intensified in the upper kilometer of the ocean (Fig. 14b), suggesting increased levels of dissipation confined to the thermocline. Here again, concomitant measurements of dissipation and energy density are requested to quantify the wind-induced dissipation below the mixed layer.

Sustaining long-term observations of the high-frequency dynamics of the ocean is thus essential to quantify the variability of such processes, to identify uncertainties and to further develop mixing parameterizations for global circulation models, which will not resolve the small-scale dynamics involved in diapycnal mixing in a near future.

Acknowledgments. The authors thank all colleagues and ship crews involved in the RREX cruises during which the moorings used in this study were deployed and recovered. We especially thank Kevin Balem for the processing of raw mooring data. Author Vic was supported by the Interdisciplinary graduate school for the blue planet (ISblue, ANR-17-EURE0015) and co-funded by a grant from the French government under the program Investissements d'Avenir. Authors Thierry 
and Lherminier were supported by the French Institute for the Exploitation of the Sea (IFREMER). Authors Mercier and Ferron were supported by the French National Center for Scientific Research (CNRS). The RREX project is funded by IFREMER, the Institut National des Sciences de l'Univers - Les enveloppes fluides et l'Environnement, Région Bretagne, Conseil Général du Finistère, and Brest Métropole. The oceanographic cruises were supported by the French Oceanographic Fleet (R/V Thalassa and R/V Atalante). We thank Lionel Renault and Caitlin Whalen for insightful discussions. Constructive comments by two anonymous reviewers are greatly appreciated.

Data availability statement. The mooring data are available online [https://www.seanoe.org/data/00443/55445/ (doi: 10.17882/55445]).

\section{REFERENCES}

Alford, M. H., 2003a: Improved global maps and 54-year history of wind-work on ocean inertial motions. Geophys. Res. Lett., 30, 1424, https://doi.org/10.1029/2002GL016614.

_ 2003b: Redistribution of energy available for ocean mixing by long-range propagation of internal waves. Nature, $\mathbf{4 2 3}$, 159-162, https://doi.org/10.1038/nature01628.

_- and M. Whitmont, 2007: Seasonal and spatial variability of near-inertial kinetic energy from historical moored velocity records. J. Phys. Oceanogr., 37, 2022-2037, https://doi.org/ 10.1175/JPO3106.1.

- - and Z. Zhao, 2007: Global patterns of low-mode internal-wave propagation. Part I: Energy and energy flux. J. Phys. Oceanogr., 37, 1829-1848, https://doi.org/10.1175/ JPO3085.1.

— J. J. MacKinnon, H. L. Simmons, and J. D. Nash, 2016: Near-inertial internal gravity waves in the ocean. Annu. Rev. Mar. Sci., 8, 95-123, https://doi.org/10.1146/annurevmarine-010814-015746.

Althaus, A. M., E. Kunze, and T. B. Sanford, 2003: Internal tide radiation from Mendocino Escarpment. J. Phys. Oceanogr., 33, 1510-1527, https://doi.org/10.1175/1520-0485(2003)033<1510: ITRFME $>2.0 . \mathrm{CO} ; 2$.

Ansong, J. K., and Coauthors, 2017: Semidiurnal internal tide energy fluxes and their variability in a global ocean model and moored observations. J. Geophys. Res. Oceans, 122, 18821900, https://doi.org/10.1002/2016JC012184.

Asselin, O., and W. R. Young, 2020: Penetration of wind-generated near-inertial waves into a turbulent ocean. J. Phys. Oceanogr., 50, 1699-1716, https://doi.org/10.1175/JPO-D-19-0319.1.

Balem, K., 2019: Surface effects on long-ranger moored ADCP (RREX case study). Ifremer Tech. Rep., 14 pp., https:// archimer.ifremer.fr/doc/00495/60624/.

Becker, J., and Coauthors, 2009: Global bathymetry and elevation data at 30 arc seconds resolution: SRTM30_PLUS. Mar. Geod., 32, 355-371, https://doi.org/10.1080/01490410903297766.

Bell, T., 1975a: Lee waves in stratified flows with simple harmonic time dependence. J. Fluid Mech., 67, 705-722, https://doi.org/ 10.1017/S0022112075000560.

_ 1975b: Topographically generated internal waves in the open ocean. J. Geophys. Res., 80, 320-327, https://doi.org/10.1029/ JC080i003p00320.

Bower, A., and H. Furey, 2017: Iceland-Scotland overflow water transport variability through the Charlie-Gibbs fracture zone and the impact of the North Atlantic current. J. Geophys. Res. Oceans, 122, 6989-7012, https://doi.org/ 10.1002/2017JC012698.

Branellec, P., and V. Thierry, 2016: RREX 2015: CTD-O2 Data report. Ifremer Tech. Rep., 357 pp., https://doi.org/10.13155/ 47156.

— , and —-, 2018: RREX 2017: CTD-O2 Data report. Ifremer Tech. Rep., 345 pp., https://doi.org/10.13155/58074.

Bühler, O., and M. Holmes-Cerfon, 2011: Decay of an internal tide due to random topography in the ocean. J. Fluid Mech., 678, 271-293, https://doi.org/10.1017/jfm.2011.115.

Chiswell, S. M., 2006: Altimeter and current meter observations of internal tides: Do they agree? J. Phys. Oceanogr., 36, 18601872, https://doi.org/10.1175/JPO2944.1.

Clément, L., A. M. Thurnherr, and L. C. St. Laurent, 2017: Turbulent mixing in a deep fracture zone on the Mid-Atlantic Ridge. J. Phys. Oceanogr., 47, 1873-1896, https://doi.org/ 10.1175/JPO-D-16-0264.1.

Copernicus, 2017: ERA5: Fifth generation of ECMWF atmospheric reanalyses of the global climate. Copernicus Climate Change Service Climate Data Store, https://cds.climate.copernicus.eu/ cdsapp\#!/home.

D'Asaro, E. A., 1985: The energy flux from the wind to nearinertial motions in the surface mixed layer. J. Phys. Oceanogr., 15, 1043-1059, https://doi.org/10.1175/1520-0485(1985)015<1043: TEFFTW $>2.0 . \mathrm{CO} ; 2$.

de Boyer Montégut, C., G. Madec, A. S. Fischer, A. Lazar, and D. Iudicone, 2004: Mixed layer depth over the global ocean: An examination of profile data and a profile-based climatology. J. Geophys. Res., 109, C12003, https://doi.org/10.1029/ 2004JC002378.

de Lavergne, C., S. Falahat, G. Madec, F. Roquet, J. Nycander, and C. Vic, 2019: Toward global maps of internal tide energy sinks. Ocean Modell., 137, 52-75, https://doi.org/ 10.1016/j.ocemod.2019.03.010.

— and Coauthors, 2020: A parameterization of local and remote tidal mixing. J. Adv. Model. Earth Syst., 12, e2020MS002065, https://doi.org/10.1029/2020MS002065.

Egbert, G. D., and S. Y. Erofeeva, 2002: Efficient inverse modeling of barotropic ocean tides. J. Atmos. Oceanic Technol., 19, 183-204, https://doi.org/10.1175/1520-0426(2002)019<0183: EIMOBO $>2.0 . \mathrm{CO} ; 2$.

Fer, I., A. Bosse, B. Ferron, and P. Bouruet-Aubertot, 2018: The dissipation of kinetic energy in the Lofoten basin eddy. J. Phys. Oceanogr., 48, 1299-1316, https://doi.org/10.1175/ JPO-D-17-0244.1.

Fernández-Castro, B., D. G. Evans, E. Frajka-Williams, C. Vic, and A. C. Naveira Garabato, 2020: Breaking of internal waves and turbulent dissipation in an anticyclonic mode water eddy. J. Phys. Oceanogr., 50, 1893-1914, https://doi.org/10.1175/ JPO-D-19-0168.1.

Ferron, B., F. Kokoszka, H. Mercier, P. Lherminier, T. Huck, A. Rios, and V. Thierry, 2016: Variability of the turbulent kinetic energy dissipation along the A25 Greenland-Portugal transect repeated from 2002 to 2012. J. Phys. Oceanogr., 46, 1989-2003, https://doi.org/10.1175/JPO-D-15-0186.1.

Flexas, M. M., A. F. Thompson, H. S. Torres, P. Klein, J. T. Farrar, H. Zhang, and D. Menemenlis, 2019: Global estimates of the energy transfer from the wind to the ocean, with emphasis on near-inertial oscillations. J. Geophys. Res. Oceans, 124, 57235746, https://doi.org/10.1029/2018JC014453.

Garrett, C., 2001: What is the "near-inertial"' band and why is it different from the rest of the internal wave spectrum? 
J. Phys. Oceanogr., 31, 962-971, https://doi.org/10.1175/15200485(2001)031<0962:WITNIB > 2.0.CO;2.

- , and E. Kunze, 2007: Internal tide generation in the deep ocean. Annu. Rev. Fluid Mech., 39, 57-87, https://doi.org/ 10.1146/annurev.fluid.39.050905.110227.

Green, J. M., and J. Nycander, 2013: A comparison of tidal conversion parameterizations for tidal models. J. Phys. Oceanogr., 43, 104-119, https://doi.org/10.1175/JPO-D-12023.1.

Gregg, M., 1989: Scaling turbulent dissipation in the thermocline. J. Geophys. Res., 94, 9686-9698, https://doi.org/10.1029/ JC094iC07p09686.

Hersbach, H., and Coauthors, 2019: Global reanalysis: Goodbye ERAInterim, hello ERA5. ECMWF Newsletter, No. 159, ECMWF, Reading, United Kingdom, 17-24, https://www.ecmwf.int/ sites/default/files/elibrary/2019/19027-global-reanalysis-goodbyeera-interim-hello-era5.pdf.

Jouanno, J., X. Capet, G. Madec, G. Roullet, and P. Klein, 2016: Dissipation of the energy imparted by mid-latitude storms in the Southern Ocean. Ocean Sci., 12, 743-769, https://doi.org/ 10.5194/os-12-743-2016.

Joyce, T. M., J. M. Toole, P. Klein, and L. N. Thomas, 2013: A nearinertial mode observed within a Gulf Stream warm-core ring. J. Geophys. Res. Oceans, 118, 1797-1806, https://doi.org/ 10.1002/jgrc.20141.

Klymak, J. M., and Coauthors, 2006: An estimate of tidal energy lost to turbulence at the Hawaiian Ridge. J. Phys. Oceanogr., 36, 1148-1164, https://doi.org/10.1175/JPO2885.1.

Köhler, J., M. Walter, C. Mertens, J. Stiehler, Z. Li, Z. Zhao, J.-S. von Storch, and M. Rhein, 2019: Energy flux observations in an internal tide beam in the eastern North Atlantic. J. Geophys. Res. Oceans, 124, 5747-5764, https:// doi.org/10.1029/2019JC015156.

Kunze, E., 1985: Near-inertial wave propagation in geostrophic shear. J. Phys. Oceanogr., 15, 544-565, https://doi.org/10.1175/ 1520-0485(1985)015<0544:NIWPIG > 2.0.CO;2.

_ , R. W. Schmitt, and J. M. Toole, 1995: The energy balance in a warm-core ring's near-inertial critical layer. J. Phys. Oceanogr., 25, 942-957, https://doi.org/10.1175/1520-0485(1995) 025<0942:TEBIAW $>2.0$. CO 2 .

Lahaye, N., and S. G. Llewellyn Smith, 2020: Modal analysis of internal wave propagation and scattering over large-amplitude topography. J. Phys. Oceanogr., 50, 305-321, https://doi.org/ 10.1175/JPO-D-19-0005.1.

Large, W., and S. Yeager, 2009: The global climatology of an interannually varying air-sea flux data set. Climate Dyn., 33, 341-364, https://doi.org/10.1007/s00382-008-0441-3.

Leaman, K. D., and T. B. Sanford, 1975: Vertical energy propagation of inertial waves: A vector spectral analysis of velocity profiles. J. Geophys. Res., 80, 1975-1978, https://doi.org/ 10.1029/JC080i015p01975.

Le Boyer, A., M. H. Alford, R. Pinkel, T. D. Hennon, Y. J. Yang, D. Ko, and J. Nash, 2020: Frequency shift of near-inertial waves in the South China Sea. J. Phys. Oceanogr., 50, 11211135, https://doi.org/10.1175/JPO-D-19-0103.1.

Le Corre, M., J. Gula, and A. M. Tréguier, 2020: Barotropic vorticity balance of the North Atlantic subpolar gyre in an eddyresolving model. Ocean Sci., 16, 451-468, https://doi.org/ 10.5194/os-16-451-2020.

Lee, D.-K., and P. P. Niiler, 1998: The inertial chimney: The nearinertial energy drainage from the ocean surface to the deep layer. J. Geophys. Res., 103, 7579-7591, https://doi.org/10.1029/ 97JC03200.
Locarnini, R., and Coauthors, 2018: Temperature. Vol. 1, World Ocean Atlas 2018, NOAA Atlas NESDIS 81, 52 pp., https:// data.nodc.noaa.gov/woa/WOA18/DOC/woa18_vol1.pdf.

Lozier, M., and Coauthors, 2019: A sea change in our view of overturning in the subpolar North Atlantic. Science, 363, 516521, https://doi.org/10.1126/science.aau6592.

McDougall, T. J., and P. M. Barker, 2011: Getting started with TEOS-10 and the Gibbs Seawater (GSW) oceanographic toolbox. SCOR/IAPSO WG127, 28 pp., http://www.teos-10.org/ pubs/Getting_Started.pdf.

Merrifield, M. A., P. E. Holloway, and T. S. Johnston, 2001: The generation of internal tides at the Hawaiian Ridge. Geophys. Res. Lett., 28, 559-562, https://doi.org/10.1029/2000GL011749.

Munk, W., and C. Wunsch, 1998: Abyssal recipes II: Energetics of tidal and wind mixing. Deep-Sea Res. I, 45, 1977-2010, https:// doi.org/10.1016/S0967-0637(98)00070-3.

Nash, J. D., M. H. Alford, and E. Kunze, 2005: Estimating internal wave energy fluxes in the ocean. J. Atmos. Oceanic Technol., 22, 1551-1570, https://doi.org/10.1175/JTECH1784.1.

Nycander, J., 2005: Generation of internal waves in the deep ocean by tides. J. Geophys. Res., 110, C10028, https://doi.org/10.1029/ 2004JC002487.

- 2006: Tidal generation of internal waves from a periodic array of steep ridges. J. Fluid Mech., 567, 415-432, https://doi.org/ 10.1017/S002211200600228X.

Olbers, D., F. Pollmann, and C. Eden, 2020: On PSI interactions in internal gravity wave fields and the decay of baroclinic tides. J. Phys. Oceanogr., 50, 751-771, https://doi.org/10.1175/JPOD-19-0224.1.

Petit, T., H. Mercier, and V. Thierry, 2018: First direct estimates of volume and water mass transports across the Reykjanes Ridge. J. Geophys. Res. Oceans, 123, 6703-6719, https://doi.org/10.1029/ 2018JC013999.

,-- , and -2019 : New insight into the formation and evolution of the East Reykjanes Ridge current and Irminger current. J. Geophys. Res. Oceans, 124, 9171-9189, https:// doi.org/10.1029/2019JC015546.

Piron, A., V. Thierry, H. Mercier, and G. Caniaux, 2017: Gyre-scale deep convection in the subpolar North Atlantic Ocean during winter 2014-2015. Geophys. Res. Lett., 44, 1439-1447, https:// doi.org/10.1002/2016GL071895.

Pollmann, F., J. Nycander, C. Eden, and D. Olbers, 2019: Resolving the horizontal direction of internal tide generation. J. Fluid Mech., 864, 381-407, https://doi.org/10.1017/jfm.2019.9.

Polzin, K., 2004: Idealized solutions for the energy balance of the finescale internal wave field. J. Phys. Oceanogr., 34, 231-246, https://doi.org/10.1175/1520-0485(2004)034<0231: ISFTEB $>2.0 . \mathrm{CO} ; 2$.

Rainville, L., and R. Pinkel, 2006: Propagation of low-mode internal waves through the ocean. J. Phys. Oceanogr., 36, 12201236, https://doi.org/10.1175/JPO2889.1.

Renault, L., M. J. Molemaker, J. C. McWilliams, A. F. Shchepetkin, F. Lemarié, D. Chelton, S. Illig, and A. Hall, 2016: Modulation of wind work by oceanic current interaction with the atmosphere. J. Phys. Oceanogr., 46, 1685-1704, https://doi.org/10.1175/JPO-D15-0232.1.

— - S. Masson, T. Arsouze, G. Madec, and J. C. McWilliams, 2020: Recipes for how to force oceanic model dynamics. J. Adv. Model. Earth Syst., 12, e2019MS001715, https://doi.org/ 10.1029/2019MS001715.

Silverthorne, K. E., and J. M. Toole, 2009: Seasonal kinetic energy variability of near-inertial motions. J. Phys. Oceanogr., 39, 1035-1049, https://doi.org/10.1175/2008JPO3920.1. 
St. Laurent, L., and C. Garrett, 2002: The role of internal tides in mixing the deep ocean. J. Phys. Oceanogr., 32, 2882-2899, https:// doi.org/10.1175/1520-0485(2002)032<2882:TROITI >2.0.CO;2.

Vic, C., A. C. Naveira Garabato, J. A. M. Green, C. Spingys, A. Forryan, Z. Zhao, and J. Sharples, 2018: The lifecycle of semidiurnal internal tides over the northern Mid-Atlantic Ridge. J. Phys. Oceanogr., 48, 61-80, https://doi.org/10.1175/ JPO-D-17-0121.1.

— scale internal tides. Nat. Commun., 10, 2099, https://doi.org/ 10.1038/s41467-019-10149-5.

Watanabe, M., and T. Hibiya, 2002: Global estimates of the windinduced energy flux to inertial motions in the surface mixed layer. Geophys. Res. Lett., 29, 1239, https://doi.org/10.1029/ $2001 \mathrm{GL} 014422$.

Waterhouse, A. F., and Coauthors, 2018: Observations of the Tasman Sea internal tide beam. J. Phys. Oceanogr., 48, 12831297, https://doi.org/10.1175/JPO-D-17-0116.1.

WAVEWATCH III Development Group, 2016: User manual and system documentation of WAVEWATCH III version 5.16. NOAA/NWS/NCEP/MMAB Tech. Rep., 361 pp., https:// polar.ncep.noaa.gov/waves/wavewatch/manual.v5.16.pdf.
Whalen, C. B., J. MacKinnon, and L. Talley, 2018: Large-scale impacts of the mesoscale environment on mixing from wind-driven internal waves. Nat. Geosci., 11, 842-847, https://doi.org/10.1038/ s41561-018-0213-6.

_ C. de Lavergne, A. C. Naveira Garabato, J. M. Klymak, J. A. MacKinnon, and K. L. Sheen, 2020: Internal wave-driven mixing: Governing processes and consequences for climate. Nat. Rev. Earth Environ., 1, 606-621, https://doi.org/10.1038/s43017-020-0097-z.

Wunsch, C., and R. Ferrari, 2004: Vertical mixing, energy, and the general circulation of the oceans. Annu. Rev. Fluid Mech., 36, 281-314, https://doi.org/10.1146/annurev.fluid.36.050802.122121.

Zhao, Z., M. H. Alford, J. A. MacKinnon, and R. Pinkel, 2010: Long-range propagation of the semidiurnal internal tide from the Hawaiian Ridge. J. Phys. Oceanogr., 40, 713-736, https:// doi.org/10.1175/2009JPO4207.1.

$\longrightarrow,-$ J. B. Girton, L. Rainville, and H. L. Simmons, 2016: Global observations of open-ocean mode- $1 \mathrm{M}_{2}$ internal tides. J. Phys. Oceanogr., 46, 1657-1684, https://doi.org/10.1175/ JPO-D-15-0105.1.

Zweng, M., and Coauthors, 2018: Salinity. Vol. 2, World Ocean Atlas 2018, NOAA Atlas NESDIS 82, 50 pp., https://data.nodc.noaa.gov/ woa/WOA18/DOC/woa18_vol2.pdf. 